\title{
Functionalized chitosan derivatives as nonviral vectors: physicochemical properties of acylated $\mathbf{N}, \mathbf{N}, \mathbf{N}$ - trimethyl \\ chitosan/oligonucleotide nanopolyplexes
}

\section{Joyce C. C. Santos, abc Pedro M. D. Moreno, bc}

Alexandra A. P. Mansur, a Victoria Leiro, bc Herman S.

\section{Mansur,a and Ana Paula Pêgo bcde}

\author{
a Center of Nanoscience, Nanotechnology and Innovation-CeNanozl, Department of Metallurgical \\ and Materials Engineering, Federal University of Minas Gerais, Av. Antônio Carlos, 6627 - Escola de \\ Engenharia - Bloco 2 - sala 2233, Pampulha, Brazil \\ E-mail: hmansur@demet.ufmg.br \\ b INEB - Instituto de Engenharia Biomédica, Universidade do Porto, Porto, Portugal \\ E-mail: apego@ineb.up.pt \\ c i3S - Instituto de Investigação e Inovação em Saúde, Universidade do Porto, Portugal \\ d FEUP - Faculdade de Engenharia da Universidade do Porto, Porto, Portugal \\ e ICBAS - Instituto de Ciências Biomédicas Abel Salazar, Universidade do Porto, Porto, Portugal
}

Originally published in Soft Matter. 2015 Nov 7;11 (41):8113-25. doi: 10.1039/c5smo1403d.

\begin{abstract}
Cationic polymers have recently attracted attention due to their proven potential for nonviral gene delivery. In this study, we report novel biocompatible nanocomplexes produced using chemically functionalized $N_{1} N, N$-trimethyl chitosan (TMC) with different $\mathrm{N}$-acyl chain lengths $\left(\mathrm{C}_{5}-\mathrm{C}_{18}\right)$ associated with single-stranded oligonucleotides. The TMC derivatives were synthesized by covalent coupling reactions of quaternized chitosan with $n$-pentanoic $\left(C_{5}\right)$, $n$-decanoic $\left(C_{10}\right)$, and $n$ octadecanoic $\left(C_{18}\right)$ fatty acids, which were extensively characterized by Fourier transform-infrared spectroscopy (FT-IR) and proton nuclear magnetic resonance ( ${ }^{1} \mathrm{H}$ NMR). These $N$-acylated TMC derivatives $\left(T M C_{n}\right.$ ) were used as cationic polymeric matrices for encapsulating anionic 18-base singlestranded thiophosphorylated oligonucleotides ( $\mathrm{s} \mathrm{SONs}$ ), leading to the formation of polyplexes further characterized by zeta potential (ZP), dynamic light scattering (DLS), binding affinity, transfection efficiency and in vitro cytotoxicity assays. The results demonstrated that the length of
\end{abstract}


the grafted hydrophobic $N$-acyl chain and the relative amino:phosphate groups ratio (N/P ratio) between the TMC derivatives and ssON played crucial roles in determining the physicochemical properties of the obtained nanocomplexes. While none of the tested derivatives showed appreciable cytotoxicity, the type of acyl chain had a remarkable influence on the cell transfection capacity of TMC-sSON nanocomplexes with the derivatives based on stearic acid showing the best performance based on the results of in vitro assays using a model cell line expressing luciferase (HeLa/Luc705).

\section{INTRODUCTION}

Since publication of the original report by Zamecnik and Stephenson 1 demonstrating that DNA oligonucleotides could inhibit Rous sarcoma virus replication in cell culture, synthetic oligonucleotides (ONs) have been used as vectors for antisense gene therapy when coupled with different nonviral vectors. $\stackrel{2-4}{-}$ Antisense oligonucleotides (AONs) are synthetic, short, single-stranded RNA or DNA molecules that have complementary sequences to targeted mRNA or precursor (pre)mRNA; selective hybridization between the AONs and the target sequence inhibits gene expression. 4.5 Because of the sequence-specific nature of the double helix, oligonucleotide-based systems offer the possibility of targeting the desired genes without affecting other genes, making such systems valuable tools to elucidate the biological roles of specific proteins and for use in various genetic-driven therapies for the treatment of human diseases. $\frac{6-8}{3}$ However, the therapeutic applications of oligonucleotide-based systems are restricted by the relatively low stability of these molecules in the presence of intra- and extracellular nucleases in biological fluids, their short half-life in vivo, and their poor intracellular penetration due to the negative charge of the single-stranded ON (ssON, having a phosphate backbone). 3

In order to increase their stability and ability to penetrate the plasma membrane, chemical modifications have been introduced; 9 however, such modified ssONs require high concentrations to achieve a good response and this with the lack of specific cell-targeting ability raises concerns with potential cytotoxicity. For this reason, novel strategies for the development of effective, accurate, specific, and nontoxic carrier vectors for ss ON delivery are needed. 3,6-8,10 Nucleic acid delivery vectors are generally classified as either viral or non-viral vectors. For safety and financial reasons, non-viral vectors (i.e., synthetic delivery systems) are the preferred method for gene delivery. $2,11,12$ However, synthetic delivery systems also present some challenges, such as low gene transfer efficiency, cytotoxicity, and lack of cell-targeting capacity. $\underline{\underline{11}}$

Cationic lipid- and cationic polymer-based systems are the major types of non-viral carriers used for biomedical applications. Cationic polymers mediate transfection via the condensation and encapsulation of negatively charged nucleic acids into particles of virus-like dimensions, providing protection from enzymatic degradation and facilitating cellular uptake and endolysosomal escape, thus representing excellent candidates for gene delivery. $\underline{13-22}$ Among the potential cationic polymers, chitosan and its derivatives are attractive potential nucleic acid vectors. Chitosan is a natural linear copolymer composed of randomly distributed $\mathrm{N}$-acetyl glucosamine and d-glucosamine, varying in composition, sequence, and molecular chain length. Because of its amine moieties, which can be protonated to impart $\mathrm{pH}$-responsiveness to the chitosan-based drug carrier systems, chitosan possesses beneficial physicochemical properties with versatility for countless therapeutic applications. Furthermore, chitosan exhibits biodegradability, a good safety profile, biocompatibility, and muco-adhesive and permeability-enhancing properties.22 However, the transfection efficiency of chitosan is low under physiological conditions because of its poor water 
solubility, aggregation, and flocculation at physiological $\mathrm{pH}\left(\mathrm{p} K_{\mathrm{a}} \sim 6.5\right)$ and the inability to release the nucleic acid after endosomal escape.22-24 Consequently, in order to overcome these disadvantages, several chemical modifications of chitosan using hydrophilic and hydrophobic moieties have been reported. $24-27$ However, modifications do not generally change the fundamental properties of chitosan, but instead introduce new properties. For example, a cationic chitosan derivative, $N, N, N$-trimethyl chitosan (TMC), which exhibits higher solubility in water over a broad range of $\mathrm{pH}$ values, including at physiological $\mathrm{pH}$, has been synthesized to have the potential for biomedical applications, such as gene delivery vectors. $\underline{12,22,24}$ The degree of quaternization of chitosan, which is desirable to improve the stability of ionic complexes with nucleic acids, plays an important role in its gene transfection efficiency and cytotoxicity. Nonetheless, the strong electrostatic interaction between TMC and nucleic acids may also restrict gene delivery inside the cells, thus leading to low transfection rates. Therefore, further improvement of the gene delivery efficiency and biocompatibility of cationic chitosan derivatives is still required. $5,12,22$

In the last decade, much progress has been made by grafting hydrophilic or hydrophobic chains to the backbone of chitosan and quaternized-chitosan derivatives. $24,28,22$ Among these novel compounds, hydrophobic group-modified chitosan has been investigated for increasing gene transfection efficiency. In a variety of settings, hydrophobic chains have been shown to alter the interaction between polyplexes (i.e., complexes formed between a polymeric vector and nucleic acid) and the cell membrane, facilitating intracellular DNA dissociation, promoting cell uptake, and enhancing the unpacking of genes from the vectors. $28,30,31$ Surprisingly, considering the enormous potential of using ssON-based systems in gene therapy, $3,6,8,31,32$ few reports have described the use of chitosan-based vectors as ssON delivery platforms. $\frac{6,731}{H}$ Here, we endeavor to demonstrate the influence of different $\mathrm{N}$-acyl chain lengths focusing on the physicochemical aspects of TMC/ssON polyplexes in terms of their chemical and biochemical stability, charge balance, and dimension, while reporting on their preliminary transfection efficiencies in an in vitro splice correction system.

\section{Experimental}

\subsection{Materials}

TMC from a fungal source (89\% deacetylated and 30\% quaternization) was supplied by Kitozyme (Belgium). Decanoyl chloride $\left[\mathrm{CH}_{3}\left(\mathrm{CH}_{2}\right)_{8} \mathrm{COCl}\right]$, valeroyl chloride $\left[\mathrm{CH}_{3}\left(\mathrm{CH}_{2}\right)_{3} \mathrm{COCl}\right]$, pyrene, acetic acid, sodium hydroxide, ethanol, methanol, and diethyl ether of analytical grade were purchased from Sigma-Aldrich (St. Louis, MO, USA). Stearic acid $\mathrm{N}$-hydroxysuccinimide ester $\left[\mathrm{CH}_{3}\left(\mathrm{CH}_{2}\right)_{15} \mathrm{CH}_{2} \mathrm{CO}-\mathrm{NHS}\right]$ was obtained from Santa Cruz Biotechnology (Santa Cruz, CA, USA). 2-(NMorpholino)ethanesulfonic acid (MES) and 4-(2-hydroxyethyl)-1-piperazineethanesulfonic acid (HEPES) were purchased from Sigma-Aldrich. The 18-base ssON 2'O-methyl-RNA (SCO705: CCUCUUACCUCAGUUACA) was purchased from Integrated DNA Technologies (IDT, USA). Lipofectamine ${ }^{\circledR} 2000$ Transfection Reagent and Dulbecco's modified Eagle's medium (DMEM) were supplied by Life Technologies, Inc. (USA). Unless indicated otherwise, deionized (DI) water (Millipore Simplicity) with a resistivity of $18 \mathrm{M} \Omega \mathrm{cm}$ was used to prepare the solutions, and the procedures were conducted at room temperature $\left(20 \pm 3^{\circ} \mathrm{C}\right)$.

\subsection{Functionalization of $\mathbf{N}, \mathbf{N}, \mathbf{N}$-trimethyl chitosan with fatty acids}


Before further chemical modification, TMC was purified. One gram of TMC was dissolved in $200 \mathrm{~mL}$ of DI water, and magnetically stirred for $2 \mathrm{~h}$. Glacial acetic acid was then added dropwise until $\mathrm{pH} 5$ was reached. The solution was diluted to $300 \mathrm{~mL}$ with DI water, and was magnetically stirred at room temperature ( $r t$ ) for $2 \mathrm{~h}$. The resulting suspension was filtered through a sintered glass filter (pore size 100-160 $\mu \mathrm{m}$, Duncan) and TMC was precipitated using an ethanol : diethyl ether (1:1) mixture and $10 \mathrm{M} \mathrm{NaOH}$ solution (dropwise) until $\mathrm{pH} 9$ was reached. The precipitated TMC was centrifuged for 5 min at $5000 \mathrm{rpm}$. The supernatant was then decanted, and the TMC in the bottom of the Falcon ${ }^{\mathrm{BD}}$ tube was washed with ethanol. The purified TMC was dissolved in DI water and lyophilized $\left(-80^{\circ} \mathrm{C} / 72\right.$ h, Labconco). The purified polymer was characterized by gel permeation chromatography (GPC). The weight average molecular weight of the purified TMC was found to be $43.3 \pm 5 \mathrm{kDa}$ (GPC in $0.33 \mathrm{M}$ $\mathrm{NaCH}_{3} \mathrm{COOH} / 0.28 \mathrm{M} \mathrm{CH}_{3} \mathrm{COOH}, \mathrm{pH}_{4}, 25^{\circ} \mathrm{C}$ ).

Next, TMC was acylated by reaction between its amine groups and the acyl chloride or $\mathrm{N}$ hydroxysuccinimide (NHS) derivatives of the corresponding fatty acids.

\subsubsection{Pentanoyl (or valeroyl, TMC-C5) and decanoyl modifications (TMC-C10)}

Dried $\left(60^{\circ} \mathrm{C}, 24 \mathrm{~h}\right.$ in a vacuum oven) purified TMC ( $50 \mathrm{mg}$ ) was added to a $0.5 \mathrm{M}$ phosphate buffer $\mathrm{pH}$ 7.4 solution $(6.2 \mathrm{~mL})$. After $12 \mathrm{~h}$ of stirring, in order to ensure total solubility, the solution was transferred to a round-bottom flask, and $9.4 \mathrm{~mL}$ of methanol was added. The mixture was magnetically stirred under reflux $\left(50^{\circ} \mathrm{C}\right)$ for $1 \mathrm{~h}$, and then, $9.4 \mathrm{~mL}$ of acyl chloride (valeroyl or decanoyl, $0.85 \mathrm{w} / \mathrm{v} \%)$ solution in methanol was added dropwise. The reaction mixture was moderately stirred under reflux $\left(50^{\circ} \mathrm{C}\right)$ for $8 \mathrm{~h}$. The resulting mixture was dialyzed (Spectra/Por 3 Dialysis Membrane, MWCO $3.5 \mathrm{kDa}$ ) against distilled water for $72 \mathrm{~h}$. The dialyzed product was lyophilized and subsequently washed with ethanol. Finally, the modified TMC- $C_{5}$ and TMC-C 10 were dispersed in DI water and lyophilized for $72 \mathrm{~h}$.

\subsubsection{Octadecanoyl (or stearyl, TMC-C18) modification}

This modification was performed as previously described. 31 Briefly, dried $\left(60{ }^{\circ} \mathrm{C}\right.$, overnight, in a vacuum oven) TMC ( $50 \mathrm{mg}$ ) was added to a $0.1 \mathrm{M} \mathrm{MES}$ buffer $\mathrm{pH} 6.5$ solution $(6.2 \mathrm{~mL}$ ) and stirred for $12 \mathrm{~h}$ at $37^{\circ} \mathrm{C}$ to ensure complete solubilization. The solution was transferred to a round-bottom flask, and methanol $(9.4 \mathrm{~mL})$ was added. The reaction mixture was magnetically stirred under reflux $\left(50^{\circ} \mathrm{C}\right)$ for $1 \mathrm{~h}$. Then, $9.4 \mathrm{~mL}$ of a solution of stearic acid $\mathrm{N}$-hydroxysuccinimide ester ( $0.26 \mathrm{w} / \mathrm{v} \%)$ in methanol was added dropwise. The resulting mixture was stirred for $24 \mathrm{~h}$, and then dialyzed using the abovementioned procedure described for TMC- $C_{5}$ and TMC- $C_{10}$. Finally, the modified TMC- $C_{1} 8$ was dispersed in DI water and lyophilized for $72 \mathrm{~h}$.

\subsubsection{Characterization}

The coupling of fatty acids on the TMC backbone was confirmed by proton nuclear magnetic resonance $\left({ }^{1} \mathrm{H}\right.$ NMR) and Fourier transform-infrared spectroscopy (FT-IR). NMR spectra were recorded on a Bruker Avance III $400 \mathrm{MHz}$ spectrometer in $2.7 \% \mathrm{DCl}$ in $\mathrm{D}_{2} \mathrm{O}: \mathrm{CD}_{3} \mathrm{OD}(1: 1)$ at $323 \mathrm{~K}$. Chemical shifts are reported in ppm ( $\delta$ units) downfield from internal tetramethylsilane.

m 
The degree of substitution (DS) with fatty acids was determined by integration of the appropriate signals (fatty acid methyl group and TMC acetyl groups) in the ${ }^{1} \mathrm{H}$ NMR spectrum, and calculated using eqn (1):

$\operatorname{DS}(\%)=\left[\frac{\int \mathrm{CH}_{3}(0.8 \text { to } 0.9 \mathrm{ppm})_{\text {Fatty Acid }}}{\int \mathrm{CH}_{3}(2 \text { to } 2.2 \mathrm{ppm})_{\mathrm{TMC}}}\right] \times 0.111 \times 100$

FT-IR was used to determine the presence of specific chemical groups in TMC and $N$-acyl TMC derivatives. FT-IR was performed over the range from 650 to $4000 \mathrm{~cm}^{-1}$ (Thermo Fischer, Nicolet 6700 ) using the attenuated total reflectance spectroscopy method (ATR). TMC and functionalized TMC flakes were placed on the ATR crystal prism (ZnSe), and 64 scans were acquired at $2 \mathrm{~cm}^{-1}$ resolution with background subtraction.

\subsection{Polyplex formation and characterization}

TMC and TMC-modified polymers were dissolved in $5 \mathrm{mM} \mathrm{HCl}$ and $20 \mathrm{mM} \mathrm{HEPES}$ containing $5 \mathrm{w} / \mathrm{v} \%$ glucose $\left(\mathrm{pH}_{7.4}\right)$ at a concentration of $3.0 \mathrm{mg} \mathrm{mL}^{-1}$. Polymer/ssON polyplexes with various N/P ratios (the N/P ratio was calculated from the quaternary amino groups of the polymer and the number of phosphate groups of the $\mathrm{ssON}$ ) were prepared by heating the polymer and $\mathrm{ssON}$ solutions separately at $60^{\circ} \mathrm{C}$ for $5 \mathrm{~min}$, followed by addition of the appropriate volume of ss $\mathrm{ON}$ solution into the polymeric solution under vortexing. The mixture was then further incubated for $10 \mathrm{~min}$ at $60^{\circ} \mathrm{C}$ under agitation (80o rpm). The mixture was finally left to cool down and stabilize at room temperature for $30 \mathrm{~min}$.

The mean hydrodynamic diameter $\left(H_{D}\right)$ and zeta potential $(Z P)$ of the polyplexes were determined using a Zetasizer Nano ZS (Malvern, UK) by photon correlation spectroscopy and electrophoretic mobility, respectively. All measurements were performed in triplicate at $25 \pm 2{ }^{\circ} \mathrm{C}$.

\subsection{Interaction strength}

The strength of interaction between TMC and ON-modified TMCs was determined by gel retardation assays using polyacrylamide gels (10-20\%) in Tris/borate/sodium ethylenediaminetetraacetic acid (EDTA) buffer (TBE buffer, containing $0.089 \mathrm{M}$ Tris base, 0.089 M boric acid, and 2 mM EDTA, pH 8.3). $T M C / O N$ particles with different N/P ratios were directly loaded into the gel. Electrophoresis was performed at a constant voltage of $110 \pm 1 \mathrm{~V}$ for $45 \mathrm{~min}$. The gels were stained with SYBR Gold nucleic acid stain and visualized using an imager (Gel Doc XR; Bio-Rad, Hercules, CA, USA).

\subsection{Nanoparticle stability in serum}

TMC/ON complexes were diluted in a $1: 3$ ratio with DMEM (containing $4500 \mathrm{mg} \mathrm{L}^{-1}$ glucose) and glutamax, supplemented with $10 \%$ fetal bovine serum (FBS, Gibco) and incubated at $37^{\circ} \mathrm{C}$ for $1 \mathrm{~h}$. The average $H_{D}$ of the polyplexes after incubation was determined by dynamic light scattering (DLS) using a Zetasizer Nano ZS (Malvern) at $25 \pm 2{ }^{\circ} \mathrm{C}$. EMSA analysis (as described above) was also employed after complexes were incubated in serum containing medium.

\section{.}




\subsection{Critical aggregation concentration (CAC) of modified TMCs}

The CAC of fatty acid-modified TMCs was measured using pyrene (Synergy Mx, BioTek Instruments, USA), which acts as a hydrophobic probe in fluorescence spectroscopy. 33-39 For CAC experiments, TMC derivative solutions were prepared in $20 \mathrm{mM} \mathrm{HEPES}$ buffer containing $5 \mathrm{w} / \mathrm{v} \%$ glucose $(\mathrm{pH} 7.4)$. A specific volume of pyrene aqueous solution (the final concentration of pyrene was controlled at 60 $\mu \mathrm{M})$ was added under vortexing ( $3 \mathrm{~s}$ ) and heated overnight to equilibrate the aggregates. The sample solutions containing pyrene $(60 \mu \mathrm{M})$ were excited using high-energy xenon flash at constant intensity (Synergy Mx). The concentration of TMCs and fatty acid-modified TMCs in solution varied from 10.0 to $2.0 \mathrm{mg} \mathrm{mL}^{-1}$. For measurement of the intensity ratio of the first $(372 \mathrm{~nm})$ and third ( $383 \mathrm{~nm}$ ) highest energy bands $\left(I_{1} / I_{3}\right)$ in the emission spectra of pyrene, the excitation wavelength was $317 \mathrm{~nm}$ with an integration time of $10 \mathrm{sm}^{-1}$. 37

\subsection{In vitro transfection}

HeLa/Luc70 5 cells were cultured in DMEM with $10 \% \mathrm{FBS}$ and $50 \mu \mathrm{g} \mathrm{mL}^{-1}$ gentamycin. HeLa cells were plated $24 \mathrm{~h}$ before transfection $\left(6 \times 10^{4}\right.$ cells per well) in 24 -well plates. On the day of transfection, the medium was replaced with DMEM containing $10 \% \mathrm{FBS}$ without antibiotics. TMC complexes were prepared as described above, and Lipofectamine ${ }^{\circledR} 2000$ was used to prepare control complexes following the manufacturer's protocols. The TMC-derivative/ssON complexes were added dropwise to each well of the plate until the final volume of $300 \mu \mathrm{L}$ was achieved, and incubation was performed for $48 \mathrm{~h}$, during which one volume of fresh complete medium (with no antibiotics) was added to the wells after $24 \mathrm{~h}$.

Cells were harvested in Hank's Krebs Ringer (HKR) lysis buffer ( $130 \mathrm{mM} \mathrm{NaCl}, 5 \mathrm{mM} \mathrm{KCl}, 1.2 \mathrm{mM}$ $\mathrm{MgSO}_{4}, 1.2 \mathrm{mM} \mathrm{CaCl}_{2}, 20 \mathrm{mM}$ HEPES, $1.2 \mathrm{mM} \mathrm{Na}_{2} \mathrm{SO}_{4}, 10 \mathrm{mM}$ glucose, $\mathrm{pH} 7.3$, with the addition of $0.15 \mathrm{v} / \mathrm{v} \%$ Triton $\mathrm{X}-100)$. The level of luciferase expression was analyzed based on a luciferase activity assay (Luciferase Assay System; Promega, Madison, WI, USA) and the total protein was measured using a BCA protein assay (BCA protein assay kit, Thermo Scientific-Pierce Protein Research Products, USA).

\subsection{Cellular interaction/uptake}

The cellular interaction of $\mathrm{TMC} / \mathrm{ssON}$ nanocomplexes was analyzed by flow cytometry analysis. Cells were seeded (60 ooo cells) $24 \mathrm{~h}$ prior to transfection in 24 -well plates. They were incubated with nanocomplexes (as described previously) for $4 \mathrm{~h}$. Chitosanase (Merk Millipore) (3 $\mathrm{mU}$ chitosanase per $\mu \mathrm{g}$ of TMC) in DMEM with $\mathrm{pH}$ adjusted to 6.5 was then added to the cells, by completely replacing the previous medium, and incubated for $1 \mathrm{~h}$ at $37^{\circ} \mathrm{C}$. Cells were then trypsinized, washed $2 \times$ with PBS and finally resuspended in PBS $+2 \%$ FBS. Cells were run on a FACSCalibur flow cytometer (BD Biosciences) and data were analyzed using FlowJo software (FlowJo, LLC).

\subsection{Cell toxicity (metabolic activity)}

HeLa/Luc70 5 cells were seeded in 24 -well plates $\left(4 \times 10^{4}\right.$ cells) $24 \mathrm{~h}$ prior to transfection in order to have $50 \%$ confluency. Nanocomplexes prepared as described previously and L2k based complexes were incubated with cells for $24 \mathrm{~h}$. The medium was then replaced with $300 \mu \mathrm{L}$ of fresh complete medium containing $10(\mathrm{v} / \mathrm{v}) \%$ resazurin (from an initial stock of $0.1 \mathrm{mg} \mathrm{mL}^{-1}$ in PBS, Sigma) in PBS. 
Cells were incubated for $1.5 \mathrm{~h}$ at $37^{\circ} \mathrm{C}$ after which $200 \mu \mathrm{L}$ of the medium was transferred to a black 96-well plate (Brand Plates, Brand GMBH, Germany) and fluorescence $\left(k_{\text {exc }}=530 \mathrm{~nm}, k_{\mathrm{em}}=590 \mathrm{~nm}\right.$ ) was measured on a multi-mode microplate reader (SynergiMX, Biotech). Results were expressed as relative fluorescence units (RFU).

\section{Results and discussion}

\subsection{Functionalization of $\mathbf{N}, \mathbf{N}, \mathbf{N}$-trimethyl chitosan with fatty acids}

TMC was functionalized with different fatty acids: valeroyl (A), decanoyl (B) and stearyl (C) chains (Scheme 1). The grafting of fatty acids was confirmed by FT-IR and ${ }^{1} \mathrm{H}-\mathrm{NMR}$.

${ }^{1} \mathrm{H}$-NMR spectra $\left(\mathrm{D}_{2} \mathrm{O}: \mathrm{MeOD}: \mathrm{DCl}\right)$ of the original and $\mathrm{N}$-acylated TMC polymers are shown in Fig. 1. As spectra were recorded in $\left(\mathrm{D}_{2} \mathrm{O}: \mathrm{MeOD}: \mathrm{DCl}\right)$, the $\mathrm{MeOH}-\mathrm{d}_{4}$ quintuplet (3.25 ppm) overlaps the $\mathrm{N}\left(\mathrm{CH}_{3}\right)_{3}$ peak (3.24 ppm), and hence for clarification, the original TMC was also recorded in $\mathrm{D}_{2} \mathrm{O}$ and shown in Fig. S1 (ESI $\underline{t}$ ). In the spectrum of the TMC sample prior to modification (Fig. IA; see Fig. S1 for TMC spectrum in $D_{2} \mathrm{O}, \mathrm{ESI} \pm$ ), the peak at $2.0 \mathrm{ppm}$ revealed the three $\mathrm{N}$-acetyl protons of the $\mathrm{N}$ acetyl glucosamine residue. The saccharide ring protons of chitosan are thought to resonate at approximately 3.4-5.0 ppm. 31,33,34 Consistent with this, TMC characteristic peaks at 3.2-3.3 and 2.0$2.1 \mathrm{ppm}$, which are assigned to hydrogen protons of the trimethylated quaternary residue $\left[-\mathrm{N}\left(\mathrm{CH}_{3}\right)_{3}\right]$ and acetylated residue $\left(-\mathrm{NCOCH}_{3}\right)$, respectively, were present in all spectra (Fig. 1 and Fig. S1, ESI \pm ), as expected. $31,33,34-36$ The incorporation of fatty acid residues was established because of the appearance of the signals corresponding to the acyl chain protons: new peaks ranging from $0.8 \mathrm{ppm}$ $\left(\mathrm{CH}_{3}-\right)$ to $2.28 \mathrm{ppm}$ corresponding to the hydrocarbon backbone of the fatty acyl residues were observed in the spectra of TMC-modified samples (Fig. 1B-E). Furthermore, DS values were calculated based on eqn (1) using the ${ }^{1} \mathrm{H}$ NMR analyses (acetamide peak as a reference) for all TMCmodified polymers, as summarized in Table 1. For all samples, DS values ranged from $1.7 \%$ to $3.8 \%$, except for the sample TMC-VA_9. The higher DS value (9.1\%) obtained specifically for TMC-C5_9 could be explained by the changes in the relative concentrations of reagents during synthesis in order to verify the capacity for improving the degree of fatty acid substitution. Notably, a DS value ranging from $1 \%$ to $10 \%$ was expected for the acylation of TMC based on the reaction conditions using buffered solutions at approximately neutral $\mathrm{pH}$ ( $\mathrm{pH}_{7.4}$, slightly above the $\mathrm{p} K_{\mathrm{a}} 6.5$ of chitosan), as was used in our experiments, where $\mathrm{N}$-acylation (primary amine groups) was preferred over $\mathrm{O}$-acylation ( $\mathrm{C}_{3}$ and $\mathrm{C} 6$ alcohol groups) of TMC. 24.39 Moreover, taking into account the relatively high degree of quaternization of TMC (approximately 30\%), calculated as previously described 31 based on the ${ }^{1} \mathrm{H}$ NMR spectrum of TMC (Fig. IA and Fig. S1, ESI \pm ), some restrictions on the $N$-acylation mechanism of TMC were expected. In particular, significant conformational and kinetic limitations were expected mostly due to the steric hindrance and balance of charges caused by the cationic trimethylquaternized amine groups $\left[-N\left(\mathrm{CH}_{3}\right)_{3}\right.$, adjacent to the reacting sites of TMC (primary amines, $\left.\left.-\mathrm{NH}_{2}\right)\right] .36$

The FT-IR spectrum of pure TMC [Fig. $2 \mathrm{~A}(\mathrm{a})]$ exhibited absorption peaks at $3400-3200 \mathrm{~cm}^{-1}(\mathrm{VOH}$ overlapped with $v \mathrm{NH}$, and hydrogen bonds), $3000-2800 \mathrm{~cm}^{-1}(v \mathrm{CH}), 1650-1640 \mathrm{~cm}^{-1}(v \mathrm{C}=\mathrm{O}$ amide $\mathrm{I})$, $1590-1570 \mathrm{~cm}^{-1}$ ( $\delta \mathrm{NH}$ primary amine), $1560-1550 \mathrm{~cm}^{-1}\left(\delta \mathrm{NH}\right.$ amide II), and $1420-1380 \mathrm{~cm}^{-1}(\delta \mathrm{CH})$. Bands at $1321 \mathrm{~cm}^{-1}, 1260 \mathrm{~cm}^{-1}$, and $1380 \mathrm{~cm}^{-1}$ were associated with the bending vibrations of primary, secondary, and tertiary amides $(\delta C-N)$, respectively. In addition, the absorption peaks at 1020-1050 $\mathrm{cm}^{-1}$ and $1070-1110 \mathrm{~cm}^{-1}$ indicated the $\mathrm{C}-\mathrm{O}$ stretching vibrations in chitosan, which are related to the $\mathrm{C} 6-\mathrm{OH}$ primary alcohol and the $\mathrm{C}_{3}-\mathrm{OH}$ secondary alcohol, respectively. The bands at $1160 \mathrm{~cm}^{-1}$ and 
$996 \mathrm{~cm}^{-1}$ were assigned to the vibrations of the $\mathrm{C}-\mathrm{O}-\mathrm{C}$ saccharide bridge. $.5 \mathrm{~A}$ characteristic band of TMC was observed at approximately $1480 \mathrm{~cm}^{-1}$, which is attributed to the asymmetric angular deformation of the methyl groups of quaternized chitosan. $\underline{27}$

FT-IR spectroscopy was also performed for a more detailed investigation of the chemical reaction leading to the formation of the acyl TMC derivatives TMC-C5_3 [Fig. 2A(b)], TMC-C5_9 [Fig. 2A(c)], TMC-C10_2 [Fig. 2A(d)], and TMC-C18_2 [Fig. 2A(e)]. By comparing the FT-IR spectra of TMC [Fig. $2 \mathrm{~A}(\mathrm{a})]$ and TMC-modified polymers [Fig. $2 \mathrm{~A}(\mathrm{~b})-(\mathrm{e})]$, the vibrational band corresponding to the primary amine groups $\left(1590-1570 \mathrm{~cm}^{-1}\right)$ was reduced due to the reaction, while the absorption band at $1555 \mathrm{~cm}^{-1}$ (amide II), which was associated with the formation of new amide bonds due to the acylation reaction, was increased. The same trend was observed for the stretching $\mathrm{C}-\mathrm{H}$ vibration band at $2920 \mathrm{~cm}^{-1}$, which was related to the $\mathrm{CH}_{2}$ groups, and its relative intensity was proportional to the acyl chain length and DS. $25,27-29$ In addition, we observed two new bands, $2960 \mathrm{~cm}^{-1}$ and 2848 $\mathrm{cm}^{-1}$, which were characteristic of fatty acids, and the amide I band was split into two bands, i.e., 1655 $\mathrm{cm}^{-1}$ and $1637 \mathrm{~cm}^{-1}$, indicating the presence of two types of amide groups (from $\mathrm{N}$-acetyl-dglucosamine repeat units and acylation reaction) due to the different intra- and intermolecular chain interactions. $27-29$

Because FT-IR may be used for performing semi-quantitative analysis using the ratio of absorbance intensities (height or peak areas), Fig. $2 \mathrm{~B}$ shows the evolution of amide II $\left(1555 \mathrm{~cm}^{-1}\right)$ and $v \mathrm{C}-\mathrm{H}(2918$ $\mathrm{cm}^{-1}$ ) bands, using the $\mathrm{C}-\mathrm{O}$ stretching band at $1070 \mathrm{~cm}^{-1}$ as an internal reference band. $\underline{24}$ The increase in these bands in the acyl TMC sample provided additional evidence of the formation of a covalent linkage between the fatty acids and the $\mathrm{NH}_{2}$ groups of the TMC chain.

\subsection{Characterization of $\mathrm{N}$-acylated-TMC/ON polyplexes}

\subsubsection{Characterization of polyplexes by DLS}

For biomedical and pharmaceutical applications, the particle size and surface charge of polyplexes are crucial factors that modulate cellular uptake of the polyplexes. 3 The formation of nanoparticles is aimed at nucleic acid protection from endonuclease degradation and enhanced cellular uptake. Generally, nanoparticles are internalized into cells easier than microparticles. 3 In particular, for nucleic acid delivery with cationic polymers, the size distribution of polyplexes will be significantly influenced by the overall balance of charges and chemical interactions between the positively charged polymer chains and the negatively charged nucleotide strands.3,8,14 For colloids and dispersions in aqueous media, particle size is most often assessed using DLS analysis by measuring the $H_{\mathrm{D}}$.

Therefore, in this study, we investigated the physicochemical properties and stability of polyplexes formed by TMC-R/ssON (i.e., $\mathrm{R}=\mathrm{N}$-acyl chain length, $\mathrm{C}_{5}, \mathrm{C}_{10}, \mathrm{C}_{18}$; ss $\mathrm{ON}=18$-base oligonucleotide) in terms of their particle size and ZP as a function of the N/P (polymer/ON) ratio. TMC-R/ssON polyplexes were prepared in $20 \mathrm{mM}$ HEPES buffer at physiological $\mathrm{pH}$ (7.4) envisaging a potential in vivo application in the future. The average particle sizes of TMC-R/ssON polyplexes as a function of the N/P ratio are shown in Fig. 3. For all the materials, the size of the resulting nanopolyplexes showed similar trends as a function of the N/P ratio (Fig. 3A). In other words, for samples with N/P ratios of more than 10, the average polyplex size typically ranged from $\sim 90$ to $300 \mathrm{~nm}$ with a polydispersity index of approximately 0.1-0.6 (Fig. 3B $)$. Notably, at lower N/P ratios (N/P = 10), both TMC/ON and 
TMC-R/ON systems formed relatively large particles compared to the corresponding samples at higher N/P ratios ( 20-160); this observation may be explained by potential aggregation of the particles. Additionally, when the N/P ratio was increased to 20 , all systems showed a significant reduction in the size of the polyplex particles. Further augmentation of the N/P ratio above 40 did not result in detectable changes in particle size, with the exception of an occasional slight increase. This phenomenon may be attributed to the aggregation of polyplexes, which may occur in the presence of higher concentrations of TMC molecules, as verified by an increase in the polydispersity index (Fig. 3B). This index involves several factors due to the complex balance of electrostatic forces between positively charged TMC derivatives (TMC-Rs) and negatively charged ONs, combined with hydrophilic and hydrophobic interactions. Additionally, some conformational restrictions of TMC-R chains are involved due to the steric hindrance of the trimethyl amine groups with grafted-acyl groups. $\frac{12,38,40}{}$ Moreover, the enhanced charge repulsion of the cationized TMC at higher N/P ratios may also explain some of the minor increases in size. Nonetheless, the $\mathrm{N}$-acyl length undeniably affected the average $H_{D}$ values of the polyplexes. As shown in Fig. $3 \mathrm{~A}$, at high N/P ratios, ranging from 80 to 160 , the average particle size decreased when the length of the acyl chain increased (TMC-R, $R$ $=C_{5}, C_{10}$, or $\left.C_{18}\right)$. In addition to the abovementioned interactions involved in the formation of polyplexes, this trend was interpreted as representing additional relevant thermodynamic contributions derived from (i) hydrophobic attractive forces between the acyl chains of TMC-Rs and the ssONs' nitrogenous bases (as these have slight apolar characteristics), leading to better condensation; 3,15,34 (ii) intra- and inter-molecular interactions between the hydrophobically modified polymer chains, resulting in a tendency for self-assembly into aggregates on the nanometer scale in an aqueous environment. Indeed, hydrophobically modified chitosan has been shown to selfaggregate with several hydrophobic domains.341-43 However, in the context of target application for nucleic acid delivery, it is important to highlight that the $H_{D}$ of most of these polyplexes, which were produced based on $\mathrm{N}$-acylated TMC/ON within the range of $100-200 \mathrm{~nm}$, are consistent with the dimensions of nonviral nanoparticles suitable for cellular endocytosis.., 3

\subsubsection{Characterization of polyplexes by measurement of the ZP}

The overall balance of electrostatic charges on the particle surface in aqueous colloidal systems is critical for determining the physicochemical stability of the particles; this can be accessed by measurement of the ZP.. Thus, the ZPs of polymers and TMC-R/ON polyplexes at N/P $=80$ are depicted in Fig. 4. In general, at physiological pH (i.e., pH 7.4), all of the systems presented a net positive charge, regardless of the presence or length of the $\mathrm{N}$-acyl chain, which is attributed to the permanent cationic characteristics of the quaternized-chitosan (TMC) used for the preparation of TMC derivatives. The most important feature of this system was that the ZP values were decreased after the ssON was added to each TMC system, indicating that the negative ssON molecules interacted with the positive TMC-R polymer. These results of ZP values for the TMC/ON polyplexes are interesting considering their potential application as a non-viral gene delivery platform, based on the observation that negatively charged cellular membranes tend to interact with positive ions, molecules, and particles. Thus, the complexes formed between the TMC derivatives developed in this study and ssONs possess a surface charge that is compatible with membrane interactions leading to cell uptake. According to the literature, the ideal ZP is slightly above or close to o $\mathrm{mV}$, because the purpose of such modifications is to enhance binding to cell membranes, while excessive positive charge can raise cell toxicity issues. 3,22,44,45 


\subsection{Stability of nanoparticles: in vitro binding affinity assay at physiological pH}

The relative in vitro binding affinity of the TMC derivatives towards ONs during the formation of polyplexes at different N/P ratios was evaluated under physiological pH conditions (20 mM HEPES buffer plus $5 \mathrm{~m} / \mathrm{v} \%$ glucose, $\mathrm{pH}=7.4$ ) using a gel retardation assay, as presented in Fig. S2, ESIt. This assay allows an evaluation of how strong is the interaction between the polymer and the ONs as unbound or weakly bound ONs will migrate through the gel when subjected to electrophoresis, whereas strongly bound ONs will remain in the wells together with the polymer (as the size of the complexes does not allow gel migration). As a general trend, at very low N/P ratios (e.g., 0.5 and 1.0), practically all samples showed low binding affinity, apparently caused by the relatively low polymer content, preventing condensation of the polyplexes. On the other hand, at high N/P ratios (typically above 6), all samples showed high binding affinity, likely as a result of the stabilization of the system due to the increase in the relative cationic strength at higher polymer concentrations, balancing the negative charge of the ONs. The complexes formulated with TMC-C18_2/ON show the highest retardation of ON mobility, suggesting the strongest binding between the polymer and the ON in comparison to unmodified, confirming previous observations 31 and the shorter chain acyl-modified polymers. In contrast, the complexes formulated with TMC-C10_2 showed the weakest gel retardation effect of all systems, even compared with the unmodified TMC polymer, indicating that the overall balance of forces involved in the complexation had deteriorated the binding affinity between the TMC-C10_2 and ON. Quantitative analysis of unbound ON was also performed on the TMC/ON polyplex samples submitted to the gel electrophoresis retardation assay (Bio-Rad imaging software, ChemiDoc ${ }^{\text {TM }}$ System, USA) and the results are presented in Fig. 5 .

\subsection{Stability of nanoparticles: in vitro binding affinity assay in the presence of serum}

The suspension of the polymeric nanoparticles in a cell culture medium containing serum can represent a strong stressor for complexes because serum proteins can adsorb onto the surfaces of the nanoparticles by electrostatic interactions and promote destabilization. Hence, preventing the possible premature disassembly of the nanoparticles is critical for their in vivo application as non-viral vectors. Thus, after diluting the medium containing serum (DMEM containing 10\% FBS), a marked increase in polyplex sizes of TMC/ON nanoparticles was observed (Fig. 6). In addition, TMCC10_2/ON completely disassembled after incubation in the medium containing serum. In contrast, the size of TMC-C18_2/ON polyplexes slightly decreased after dilution with DMEM containing 10\% serum, possibly because some level of protein interaction with stearyl chains may lead to conformational rearrangements leading to different aggregation behavior. These data suggested that the stearyl groups can promote an enough colloidal stability of the polyplex system capable of withstanding the potential disaggregation forces caused by protein interactions with the polyplex surface or may also have caused some level of suppression of serum protein adsorption at the nanoparticle surface by generating thermodynamically triggered repulsion forces and entropically mediated interfacial water layers, preventing protein adsorption.

PAGE analysis of TMC/ON particles after serum incubation, in general and as expected, showed a tendency for destabilization of the particles with consequent increased release of ON during gel electrophoresis, when compared to no serum incubation. This destabilization is more prominent at lower N/P ratios for all the polymers tested. With increasing N/P ratios (especially above 80 ) the 
destabilization is less visible as differences between released ON before and after serum incubation are smaller, the exception being TMC-C10/ON which at N/P 160 still releases a significant amount of ON in comparison to the other polymers tested (Fig. 6).

The decreased destabilization by serum proteins seen at higher N/P ratios can result from the excess TMC molecules that are loosely bound to the particle surface and freely exist in solution, which compromise the adsorption of serum components, or the relative excess of polymer compared to ONs, potentially resulting in more effective TMC/ON interactions. The TMC-C18_2/ON nanoparticles showed the highest ability to condense the ONs as compared with all other polymers. This result supported the results described above performed at physiological $\mathrm{pH}$ without the interference of serum in the medium and the assessment of the nanoparticle $H_{D}$ by DLS analysis. We can conclude that the length of the 18 -acyl chain grafted to the TMC backbone promoted the most effective polymer/ON interactions because of the overall balance of electrostatic, hydrophilic and hydrophobic forces.

\subsection{Critical aggregation concentration (CAC)}

The study of polymer aggregation is considered interesting because this phenomenon may affect the biological activity of TMC and its derivatives. Polymer chains begin to aggregate with each other when their concentration in solution is above the CAC.42,43 The aggregates of hydrophobically modified chitosan are promising carriers for drug delivery due to the unique properties of chitosan combined with the presence of hydrophobic moieties. Understanding the impact of the hydrophobic substituents on the size and aggregation of the polymer in solution is quite important for designing drug-carrying vehicles.42 Thus, to examine this effect in more detail, we evaluated the aggregation behavior of $\mathrm{N}$-acylated TMCs in aqueous media by fluorometry in the presence of pyrene as a fluorescent probe.41 In brief, when pyrene coexists with aqueous polymeric micelles or other hydrophobic microdomains, it preferably lies close to or inside these microdomains, causing strong light emission. Therefore, when pyrene is present with self-aggregated TMC derivatives, the total emission intensity increases, and the third highest vibrational band $I_{3}(383 \mathrm{~nm})$ is abruptly increased at certain concentrations of the polymer; this is referred to as the CAC. CAC values can be determined by measuring the intensity ratio of $I_{1}(372 \mathrm{~nm})$ and $I_{3}(383 \mathrm{~nm})$.

In this study, changes in the intensity ratios $\left(I_{1} / I_{3}\right)$ of TMC and chemically modified TMC derivative aggregates were calculated. For all TMC samples, at lower concentrations, $I_{1} / I_{3}$ values remained nearly unchanged. After further increasing the concentration, the intensity ratio started to decrease with the addition of polymeric amphiphiles above the CAC. Therefore, the critical aggregation concentration values were determined by the intercept of two straight lines, based on the literature, ${ }^{42}$ and the results were TMC $=0.210 \mathrm{mg} \mathrm{mL}^{-1}, \mathrm{TMC}^{-C_{10}} 2=0.199 \mathrm{mg} \mathrm{mL}^{-1}$ and TMC-C18_2 $=0.329 \mathrm{mg} \mathrm{mL}^{-1}$. From these data, we found that TMC and TMC-C10-2 exhibited similar CAC values ( 0.200), very different from the value of approximately 0.33 (65\%) obtained for TMC-C $18-2$, which had the longest length of the acyl chain grafted to the TMC backbone. These results indicated that increasing the length of the acyl chain of the TMC derivatives significantly affected the thermodynamic stability of the polymeric micelles in aqueous solutions. Such behavior may be a result of a combination of attractive and repulsive electrostatic forces of the permanent positive charges of the amino-quaternized groups of TMC and its derivatives as well as interactions of the hydrophobic chains in aqueous medium, which is different from other systems using non-quaternized chitosan. 42,43 


\subsection{In vitro transfection: luciferase splicing reporter assay}

The HeLa/pLuc705 splice-switching reporter cell line has been previously proposed as a suitable in vitro model for delineating the properties of oligonucleotide delivery vectors. 47 Thus, in order to evaluate the effects of the fatty acid chain length of modified TMCs on the ability of the resulting complexes to mediate oligonucleotide delivery, $\mathrm{HeLa} / \mathrm{Lu}$ C705 cells were transfected with complexes prepared with TMC and chemically modified TMC derivatives (TMC-R). For each polymer, the effects of polyplex composition (i.e., the N/P ratio) were studied by assessing luciferase activity using Lipofectamine ${ }^{\circledR} 2000$ as a positive control in the transfection experiment (reference standard, a commercially available cationic lipid-based reagent). The N/P molar ratios tested were 80, 120, and 160 as minimum levels of serum stability could only be obtained at high N/P ratios (Fig. 6). Gene expression was assessed $48 \mathrm{~h}$ post-transfection (Fig. 7). As a general trend, an increase in transfection activity after the $\mathrm{N}$-acylation of TMC was observed for all samples. For TMC-C10_2/ON and TMC$\mathrm{C}_{5} 3 / \mathrm{ON}$ complexes, the results of the transfection activity were modestly higher compared to that of $\mathrm{TMC}_{43} / \mathrm{ON}$ complexes. An increase in the grafting density of $\mathrm{C}_{5}$ units in TMC ( $9 \% \mathrm{vs}$. $3 \%$ ) promoted an increase in transfection efficiency, which goes in line with the more favorable properties found for TMC-C 5 9 in relation to TMC-C 5 -3 during this study. The TMC-C18_2/ssON complexes were shown to mediate the best transfection efficiency confirming the best characteristics found in the described characterization experiments. These results are in agreement with our previous findings 33 in which a nearly 10 -fold increase in efficiency in relation to TMC/ssON and about $50 \%$ efficacy when compared to Lipofectamine ${ }^{\circledR} 2000$ alone (the positive control) have been determined. These findings strongly support the hypothesis that increasing the length of the hydrophobic chain of the fatty acid grafted to the amino-quaternized chitosan from 5 to 18 carbons promoted the formation of TMC-C 18 polyplexes with the best transfection response. In addition, the degree of substitution, although not studied in its entirety, also seems to play a role in the formation of transfection competent complexes judging from the results of TMC- $C_{5}$ with different degrees of substitution (\% DS). Based on the

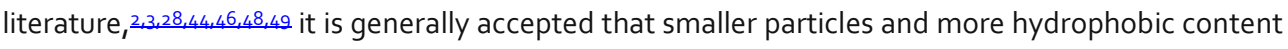
enhance transfection by facilitating the entry of the polyplexes into the cells by endocytosis, in addition to inducing better $\mathrm{ON}$ condensation and polymer interactions with the cell membrane. Nonetheless, the balance of positive (polymer/ONs) and negative (cell membrane) charges must also be considered for the development of nonviral gene delivery platforms. Consistent with this potential application, among the different nanoparticles prepared with the different chitosan derivatives, the TMC-C18 based polyplexes tested in this study exhibited several key characteristics that may help to overcome the limitations for achieving effective transfection, such as those associated with electrostatic charges (attraction, repulsion), hydrophilic and hydrophobic interactions, biochemical stability in media, and most importantly, adequate dissociation of the TMC-C18/ssON polyplex inside the cells under dynamic metabolic microenvironmental conditions.

\subsection{Cellular interaction/uptake}

The correlation between the functional effect of TMC/ssON complexes, as evaluated by the luciferase activity assays, and the degree of cellular interaction of the complexes was then examined. $\mathrm{TMC} / \mathrm{ss} \mathrm{ON}$ nanocomplexes, in three different N/P ratios $(80,120,160)$, formed with a fluorescently labeled ON were used in flow cytometry experiments (Fig. 8). Cells were analyzed after $4 \mathrm{~h}$ incubation with the nanocomplexes. Of notice is the fact that this method can only give information on the total cellular association without discriminating between membrane-associated or internalized ONcomplexes. The results showed a complete shift in the population of cells associated with Cy5 
fluorescence. Cells treated with TMC-C18-based nanoparticles showed the highest fluorescence intensity for all N/P ratios in comparison to all other TMC nanoparticles and control free ON, but below L2k.

The higher hydrophobicity imparted by the $C_{1} 8$ chains seems to play an important role in the initial interaction of the nanocomplexes with the cells. Still, in general, an increase in hydrophobicity improves cellular interactions of the TMC/sSON nanocomplexes as verified for the TMC- $C_{5} 5$ and TMC-C18. The nanocomplexes formed with TMC-C10 did not follow this rule, which, however, goes in line with the overall instability of such nanocomplexes demonstrated in the previous experiments.

\title{
3.8. Cell toxicity (metabolic activity)
}

Cell viability was evaluated by measuring metabolic activity after incubation with the $\mathrm{TMC} / \mathrm{ssON}$ nanocomplexes at different N/P ratios (Fig. 9). Independently of the nanocomplexes tested no significant alterations of the metabolic activity of the cells have been observed indicating absence of cytotoxicity by the TMC/ssON nanocomplexes.

\section{Conclusions}

In this study, quaternized-chitosan was successfully functionalized with different acyl chain lengths. The ability of the obtained acyl-TMC derivatives to form polyplexes with 18 -base ssONs by assessing the $H_{D}, Z P$, and electrophoretic characteristics was then investigated. The results demonstrated that the length of the acyl chains greatly influences the formation and physicochemical characteristics of polyplexes at the different N/P ratios tested. The stability of the formed polyplexes is perhaps one of the most important characteristics influenced by the acyl chain length, with the longest chain conferring resistance to serum destabilization and, ultimately, better transfection efficiency. The in vitro transfection assays using $\mathrm{HeLa} / \mathrm{Luc70} 5$ cell culture showed an effect of $\mathrm{N}$-acyl chain length and degree of substitution on the extent of cellular interaction and transfection ability of the polyplexes, perfectly correlating with the physicochemical characteristics observed for the different systems. This study opens up the possibility of further enhancement of transfection capacity by rational design of conjugated acyl units grafted to the chitosan polymer backbone, envisaging future in vivo applications.

\section{Conflicts of interest}

The authors declare that they have no competing or conflicting interests.

\section{Acknowledgements}

We acknowledge the financial support from the following Brazilian agencies: CAPES, FAPEMIG, CNPq, and FINEP. This work was co-financed by Fundação para a Ciência e a Tecnologia (FCT, Portugal) within the projects PTDC/CTM-NAN/NAN/115124/2009 and HMSP-ICT/0020/2010. Additionally, PMDM thanks the European Commission - Marie Curie Actions (PIEF-GA-2011-300485) for the postdoctoral fellowship. VL thanks the FCT for the postdoctoral fellowship (SFRH/BPD/69110/2010). We are grateful to Dr Sandhra Carvalho (UFMG, Brazil) for the bioimaging analyses. The authors acknowledge the Centro de Materiais da Universidade do Porto (CEMUP) for SEM and ${ }^{1} \mathrm{H}$ NMR analysis.

\author{
政
}




\section{References}

1 M. L. Stephenson and P. C. Zamecnik, Inhibition of Rous sarcoma viral RNA translation by a specific oligodeoxyribo-nucleotide,Proc. Natl. Acad. Sci. U. S. A., 1978,75, 285-288.

2 X. Guo and L. Huang, Recent advances in nonviral vectors for gene delivery, Acc. Chem. Res., 2012,45, 971-979.

$3 \mathrm{H}$. Gao, Amino poly(glycerol methacrylate)s for oligonucleic acid delivery with enhanced transfection efficiency and low cytotoxicity, Soft Matter, 2011,7, 9239-9247.

4 N. Dias and C. A. Stein, Antisense oligonucleotides: basic concepts and mechanisms, Mol. Cancer Ther., 2002,1, 347.5 C. P. Gomes, C. F. Lopes, P. D. Moreno, A. Varela-Moreira, M. J. Alonso and A. P. Pêgo, Translating chitosan to clinical delivery of nucleic acid-based drugs MRS Bull., 2014,39,60-70.

6 B. Enneli, S. O. Turan, B. Uslu and J. Akbuga, In vitro antisense activity of chitosan/as ODN complexes, Adv. Mol.Biol., 2009,3, 27-34.

7 H.-J. Hong, S.-E. Jin, J.-S. Park, W. S. Ahn and C.-K.Kim, Accelerated wound healing by smad3 antisenseoligonucleotides-impregnated chitosan/alginate polyelectrolyte complex, Biomaterials, $2008,29,4831-4837$.

8 T. Gazori, M. R. Khoshayand, E. Azizi, P. Yazdizade,A. Nomani and I. Haririan, Evaluation of alginate/chitosan nanoparticles as antisense delivery vector: formulation, optimization and in vitrocharacterization, Carbohydr. Polym., 2009,77, 599-606.

9 P. M. Moreno and A. P. Pêgo, Therapeutic antisense oligo-nucleotides against cancer: hurdling to the clinic, Front. Chem., 2014, 2, 1-7.

10 A. Philipp and E. Wagner, Receptor-targeted polyplexes forDNA and siRNA delivery, inGene and Cell Therapy Therapeutic Mechanisms and Strategies, ed. N. S. Templeton, CRC Press, Taylor \& Francis Group, Boca Raton, 3rd edn, 2009,ch. 15.

11 Q. Xu, C.-H. Wang and D. W. Pack, Polymeric carriers forgene delivery: chitosan and poly(amidoamine) dendrimers, Curr. Pharm. Des., 2010, 16, 2350-2368.

$12 \mathrm{Z}$. Mao, The gene transfection efficiency of thermoresponsive $\mathrm{N}, \mathrm{N}, \mathrm{N}$-trimethyl chitosan chlorideg-poly(N-isopropylacrylamide)copolymer, Biomaterials, 2007, 28, 4488-4500.

13 R. K. Oskuee, A. Philipp, A. Dehshahri, E. Wagner andM. Ramezani, The impact of carboxyalkylation of branchedpolyethylenimine on effectiveness in small interfering RNAdelivery, J. Gene Med., 2010,12, 729-738.

14 D. Liu, T. Ren and X. Gao, Cationic transfection lipids, Curr.Med. Chem., 2003,10, 1307-1315.15 N. Duzgunes, C. T. De Ilarduya, S. Simões, R. I. Zhdanov,K. Konopka and M. C. Pedroso de Lima, Cationic liposomesfor gene delivery: novel cationic lipids and enhancement by proteins and peptides, Curr. Med. Chem., 2003, 10, 1213-1220. 
16 S. L. Hart, Lipid carriers for gene therapy, Curr. Drug Delivery, 2005, 2, 423-428.

17 W. Li, F.C. Szoka, Jr. Lipid-based nanoparticles for nucleic acid delivery ,Pharm. Res., 2007, 24, 438-449.

18 S. C. De Smedt, J. Demeester and W. E. Hennink, Cationic polymer based gene delivery systems, Pharm. Res., 2000, 17,113-126.

19 D. W. Pack, A. S. Hoffman, S. Pun and P. S. Stayton, Design and development of polymers for gene delivery, Nat. Rev.Drug Discovery, $2005,4,581-593$.

20 M. J. Tiera, F. O. Winnik and J. C. Fernandes, Synthetic andnatural polycations for gene therapy: state of the art andnew perspectives, Curr. Gene Ther., 2006, 6, 59-71.

21 D. Schaffert and E. Wagner, Gene therapy progress andprospects: synthetic polymer based systems, Gene Ther., 2008, 15, 1131-1138.

22 S. K. Samal, Cationic polymers and their therapeuticpotential,Chem. Soc. Rev., 2012, 41, 71477194 .

23 R. Jayakumar, K. P. Chennazhi, R. A. A. Muzzarelli,H. Tamura, S. V. Nair and N. Selvamurugan, Chitosanconjugated DNA nanoparticles in gene therapy, Carbohydr.Polym., 2010, 79, 1-8.

24 T. Kim, H. Jiang, D. Jere, I. Park, M. Cho, J. Nah, Y. Choi,T. Akaike and C. Cho, Chemical modification of chitosan asa gene carrierin vitroandin vivo,Prog. Polym. Sci., 2007, 32,7 26-753.

25 J. C. C. Santos, A. A. P. Mansur and H. S. Mansur, One-stepbiofunctionalization of quantum dots with chitosan andN-palmitoyl chitosan for potential biomedical applications,Molecules, 2013,18 , $6550-6572$.

26 C. Moreira, H. Oliveira, L. Pires, S. Simões, M. A. Barbosaand A. P. Pêgo, Improving chitosanmediated gene transferby the introduction of intracellular buffering moieties intothe chitosan backbone,Acta Biomater., 2009, 5, 2995-3006.

27 H.S.Mansur,A.A.P.Mansur,M.V.DeAlmeidaandE.Curti,Functionalized-chitosan/quantum dots nano-hybrids for nano-medicine applications: towards biolabeling and biosorbingphosphate metabolites,J. Mater. Chem., 2013, 1, 1696-1711.

28 B. Layek and J. Singh, N-hexanoyl,N-octanoyl and N-decanoylchitosans: binding affinity, cell uptake and transfection, Carbohydr. Polym., 2012, 89, 403-410.

29 C. Le Tien ,N-acylated chitosan: hydrophobic matrices forcontrolled drug release, J. Controlled Release, 2003,93, 1-13.

30 A. P. Pêgo, H.Oliveira and P. Moreno, Biomaterial-based vectors for targeted delivery of nucleic acids to the nervous system, in Drug Delivery Systems: Advanced Technologies Potentially 
Applicable in Personalised Treatment, ed. J. Coelho, Advances in Predictive, Preventive and Personalised Medicine,vol. 4, 2013.

31 P. M. D. Moreno, J. C. C. Santos, C. P. Gomes, A. V. Moreiraand A. Pego, Modified chitosan biopolymers for efficientnanoparticle formation and transfection of splice switchingoligos, Hum. Gene Ther., 2014, 25, A74.

32 E. M. Straarup, N. Fisker, M. Hedtjärn, M. W. Lindholm, C. Rosenbohm, V. Aarup, H. F. Hansen, H. Ørum, J. B. Hansen and T. Koch, Short locked nucleic acid anti-sense oligonucleotides potently reduce apolipoprotein BmRNA and serum cholesterol in mice and non-humanprimates,Nucleic Acids Res., 2010, 38, 7100-7111.

33 V. K. Mourya and N. N. Inamdar, Trimethyl chitosan and itsapplications in drug delivery, J. Mater. Sci., 2009, 20, 1057-1079.

34 A. Jintapattanakit, S. Mao, T. Kissel and V. B. Junyaprasert, Physicochemical properties and biocompatibility ofN-trimethylchitosan: effect of quaternization and dimethylation,Eur.J. Pharm. Biopharm., 2008 ,70, 563-571.

35 A. F. Martins, P. V. Bueno, H. D. Follman, S. R. Nocchi, C. V. Nakamura, A. F. Rubira and E. C. Muniz, Synthesis, characterization, and cytotoxicity of TMC-graft-poly(vinylalcohol) copolymers, Carbohydr. Res., 2013, 381, 153-160.

36 A. B. Sieval, M. Thanou, A. F. Kotze, J. C. Verhoef, J. Brusseeand H. E. Junginger, Preparation and NMR characterization ofhighly substitutedN-trimethyl chitosan chloride,Carbohydr.Polym., 1998, $36,157-165$.

37 J. You, F.-O. Hu, Y.-Z. Du and H. Yuan, Polymeric micelleswith glycolipid-like structure and multiple hydrophobicdomains for mediating moleculartarget delivery of paclitaxel,Biomacromolecules, 2007, 8, 2450-2556.

38 X. Liang, H. Tian, H. Luo, H. Wang and J. Chang, Novelquaternized chitosan and polymeric micelles with cross-linked ionic cores for prolonged release of minocycline,J. Biomater. Sci., Polym. Ed., 2009, $20,115-131$.

39 R. S. Chiandotti, P. C. Rodrigues and L. Akcelrud, Graftingof chitosan with acyl derivatives,J. Braz. Chem. Soc., 2010, 21, 1910-1916.

40 J. Kumirska, M. Czerwicka, Z. Kaczyn'ski, A. Bychowska,K. Brzozowski, J. Thöming and P. Stepnowski, Application of spectroscopic methods for structural analysis of chitinand chitosan, Mar. Drugs, 2010,8, 1567-1636.

41 M. N. V. R. Kumar, R. A. A. Muzzarelli, C. Muzzarelli,H. Sashiwa and A. J. Domb, Chitosan chemistry and phar-maceutical perspectives, Chem. Rev., 2004,104, 6017-6084.

42 O. E. Philippova and E. V. Korchagina, Chitosan and itshydrophobic derivatives: preparation and aggregation indilute aqueous solutions, Polym. Sci., Ser. A, 2012, 54, 552-572. 
$43 \mathrm{H}$. W. Jo and K. Y. Lee, Physicochemical characteristics of self-aggregates of hydrophobically modified chitosans, Langmuir, 1998, 14, 2329-2332.

44 F. Talaei, E. Azizi, R. Dinarvand and F. Atyabi, Thiolated chitosan nanoparticles as a delivery system for antisensetherapy: evaluation against EGFR in T47D breast cancer cells, Int. J. Nanomed., 2011,6, 1963-1975.

45 A. C. Hunter, Molecular hurdles in polyfectin design and mechanistic background to polycation induced cytotoxicity,Adv. Drug Delivery Rev., 2006,58, 1523-1531.

46 A. Gallas, C. Alexander, M. C. Davies, S. Puri and S. Allen, Chemistry and formulations for siRNA therapeutics, Chem.Soc. Rev., 2013,42, 7983-7997.

47 P. Guterstam, M. Lindgren, H. Johansson, U. Tedebark, J. Wengel, S. El Andaloussi and U. Langel, Splice-switchingefficiency and specificity for oligonucleotides with lockednucleic acid monomers, Biochem. J., 2008,412, 307-313.

48 I. Messai, D. Lamalle, S. Munier, B. Verrier, Y. Ataman-Onaland T. Delair, Poly(DL-lactic acid) and chitosan complexes:interactions with plasmid DNA, Colloids Surf., A, 2005, 255,65-72.

49 J. L. Cohen, Acid-degradable cationic dextran particles forthe delivery of siRNA therapeutics,Bioconjugate Chem.,2011,22, 1056-1065. 


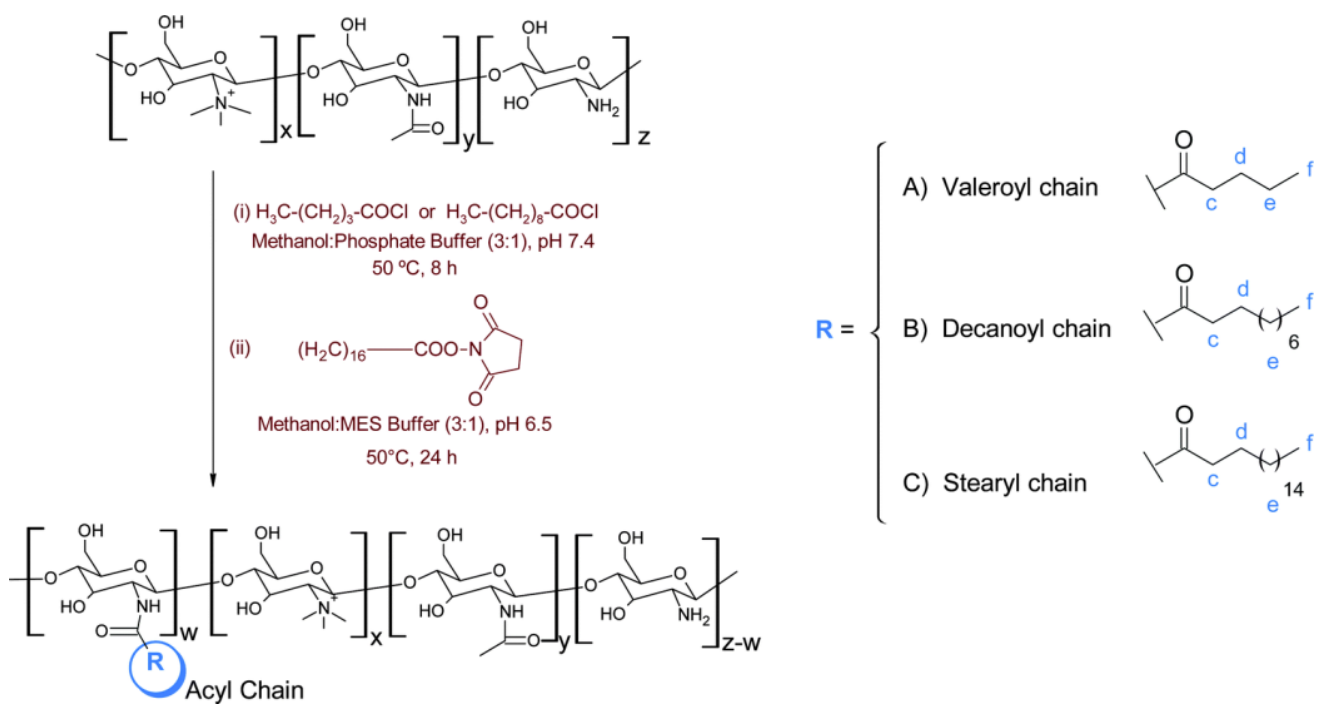

Scheme 1 Synthesis of $N$-acylated functionalized TMC polymers.

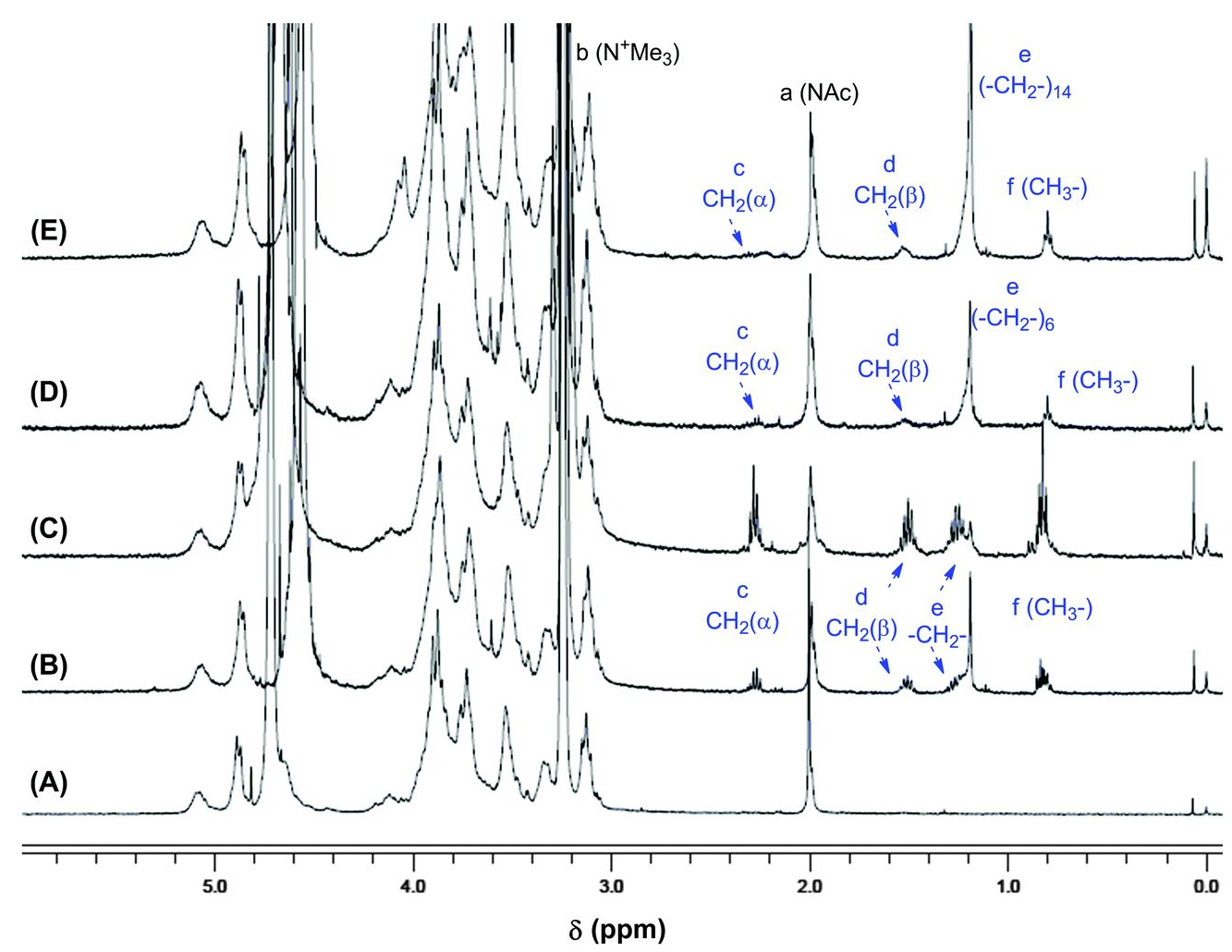

Fig. $1^{1} \mathrm{H}$ NMR spectra of TMC and TMC functionalized polymers with fatty acids $[(A) T C M ;(B)$ TMCC5_3; (C) TMC-C5_9; (D) TMC-C10_2; (E) TMC-C18_2]. 


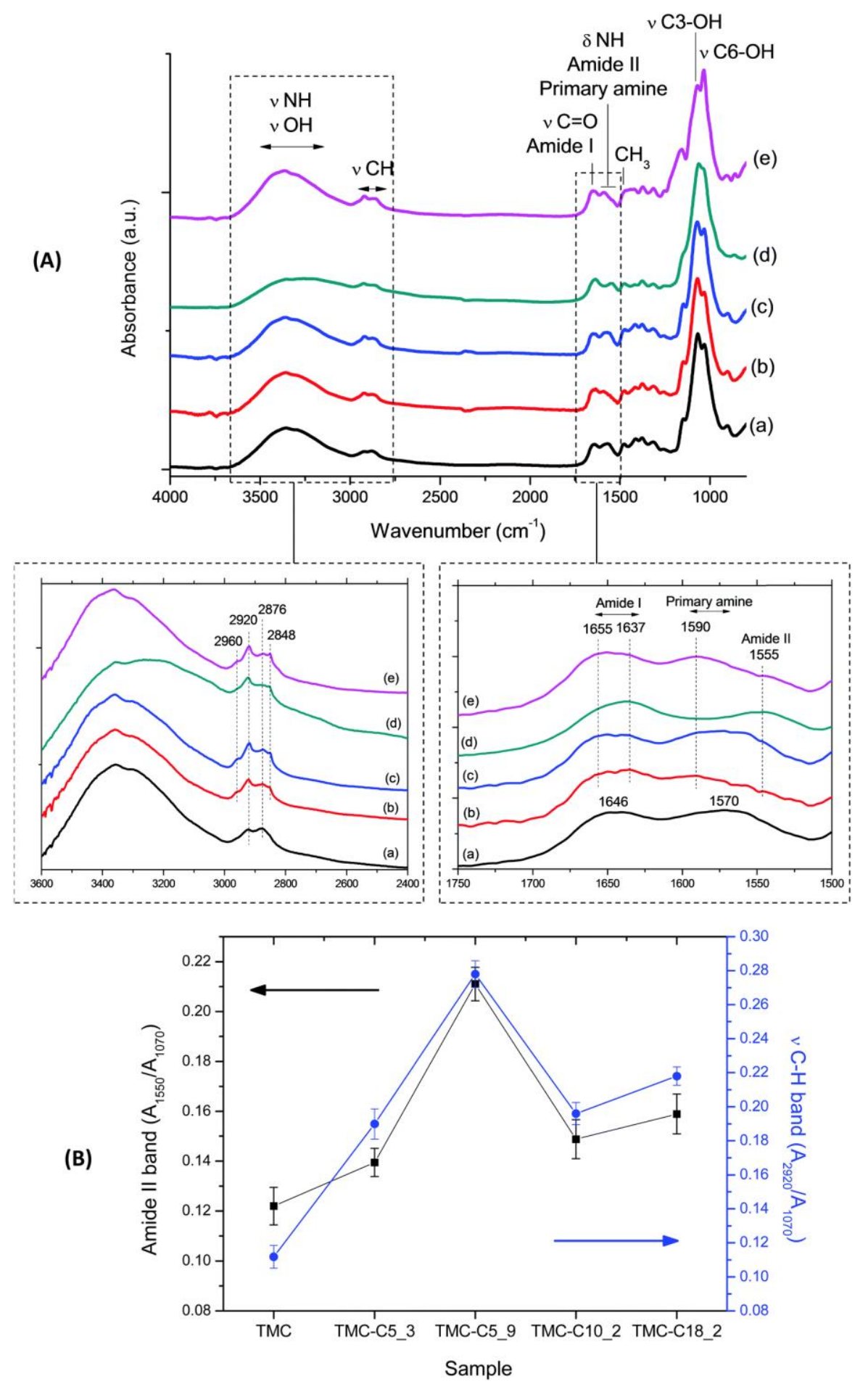

Fig. 2 (A) FT-IR spectra of TMC (a) and TMC fatty acid polymers TMC-C5_3 (b), TMC-C5_9 (c), TMC$\mathrm{C}_{10} \_2(\mathrm{~d})$, and TMC-C18_2 (e). (B) Evolution of the amide II band (squares) and $v \mathrm{C}-\mathrm{H}$ band (circles) due to the TMC/fatty acid coupling reaction. 

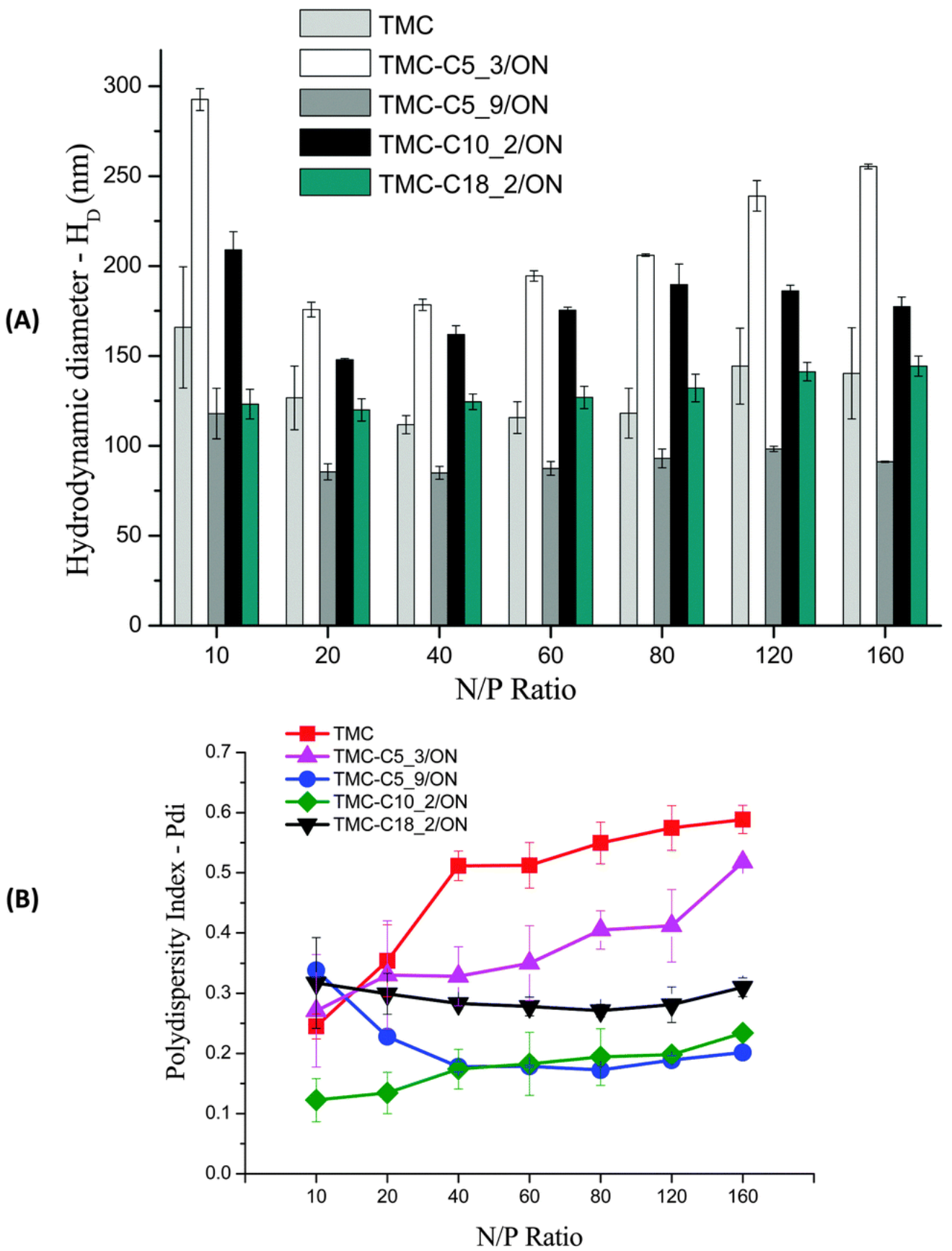

Fig. 3 (A) Average particle size [hydrodynamic diameter $\left(H_{D}\right)$ ] of TMC-R/ssON complexes as a function of the N/P ratio (N/P range from 10 to 160). (B) Polydispersity index (Pdi) of TMC/ON complexes as a function of the N/P ratio. 


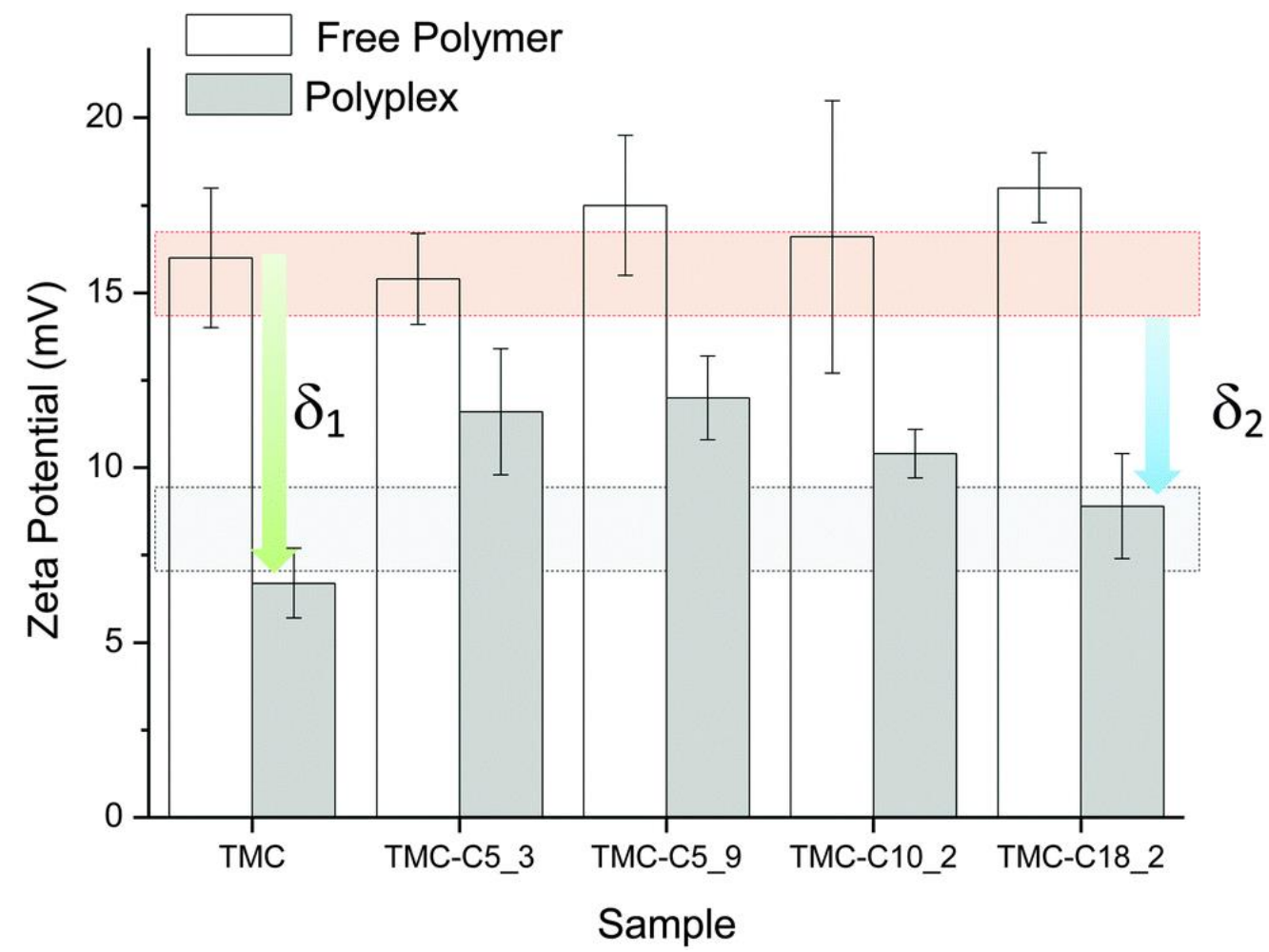

Fig. 4 Zeta potential of TMC, $N$-acylated TMC derivatives, TMC/ssON, and $N$-acylated TMC/ON polyplexes $(\mathrm{N} / \mathrm{P}=80)$.

Rua Alfredo Allen, 208 4200-135 Porto 


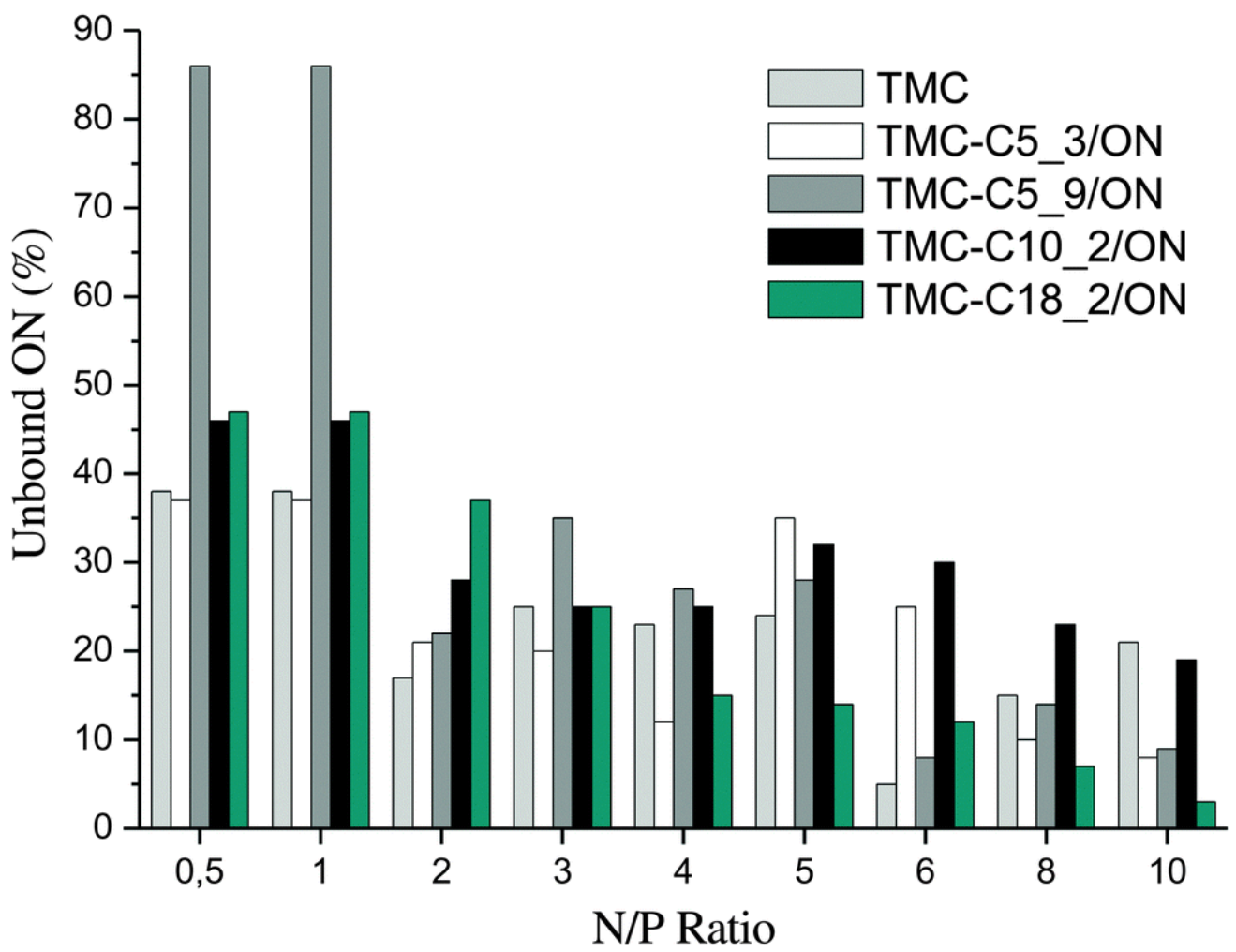

Fig. 5 Evaluation of ON release by TMC/ssON polyplexes in vitro at different N/P ratios in $20 \mathrm{mM}$ HEPES buffer plus $5 \mathrm{~m} / \mathrm{v} \%$ glucose, $\mathrm{pH}=7.4$. 


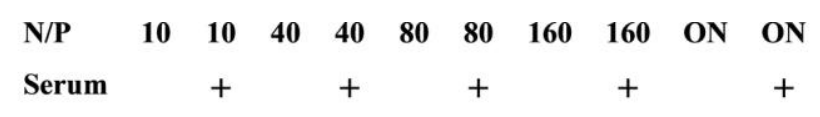

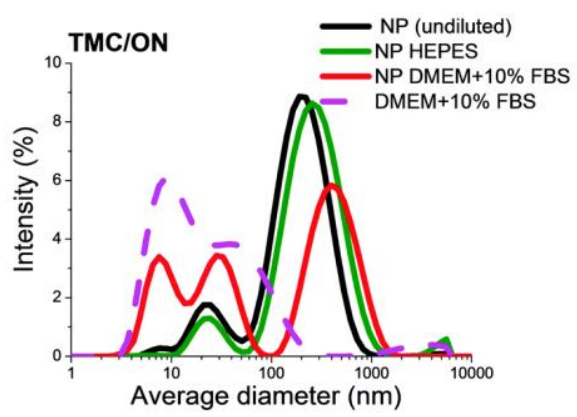

TMC/ON
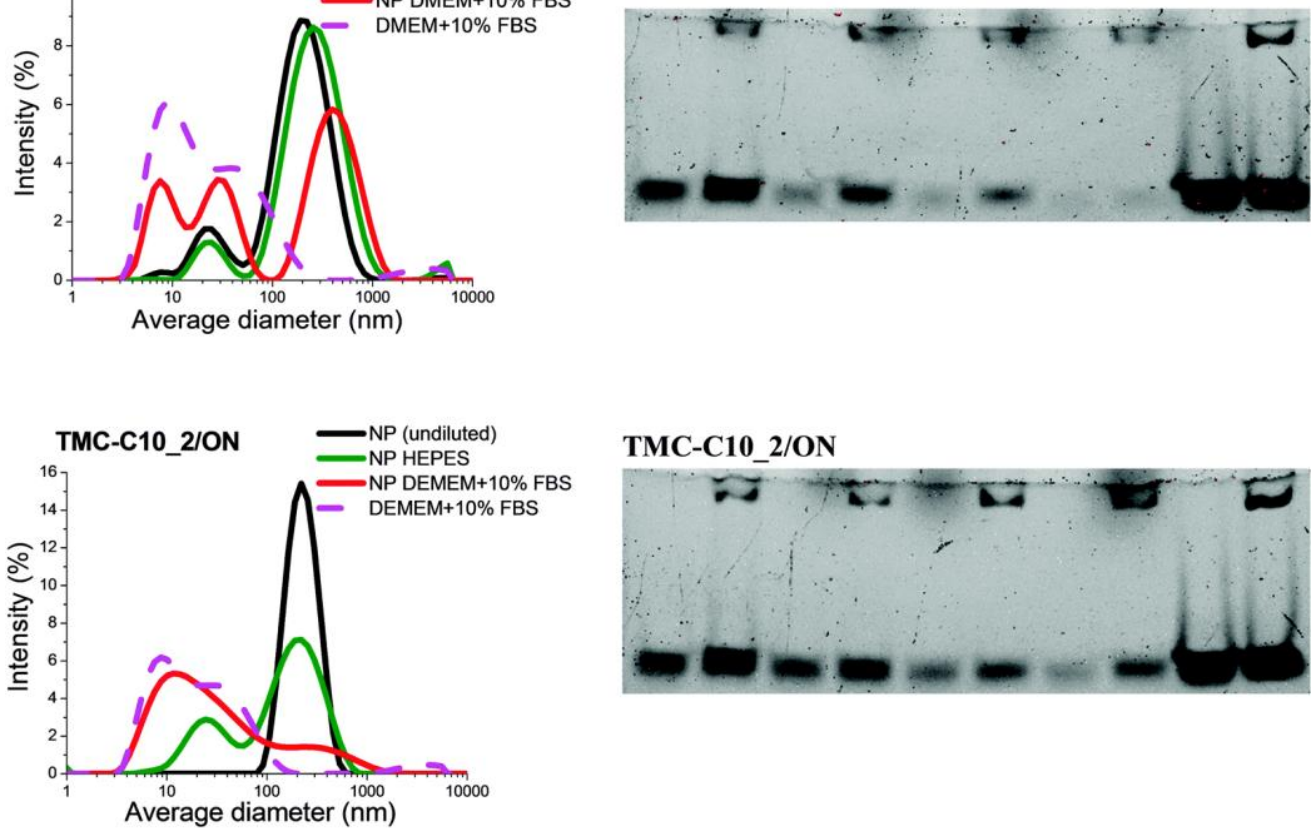

TMC-C10_2/ON
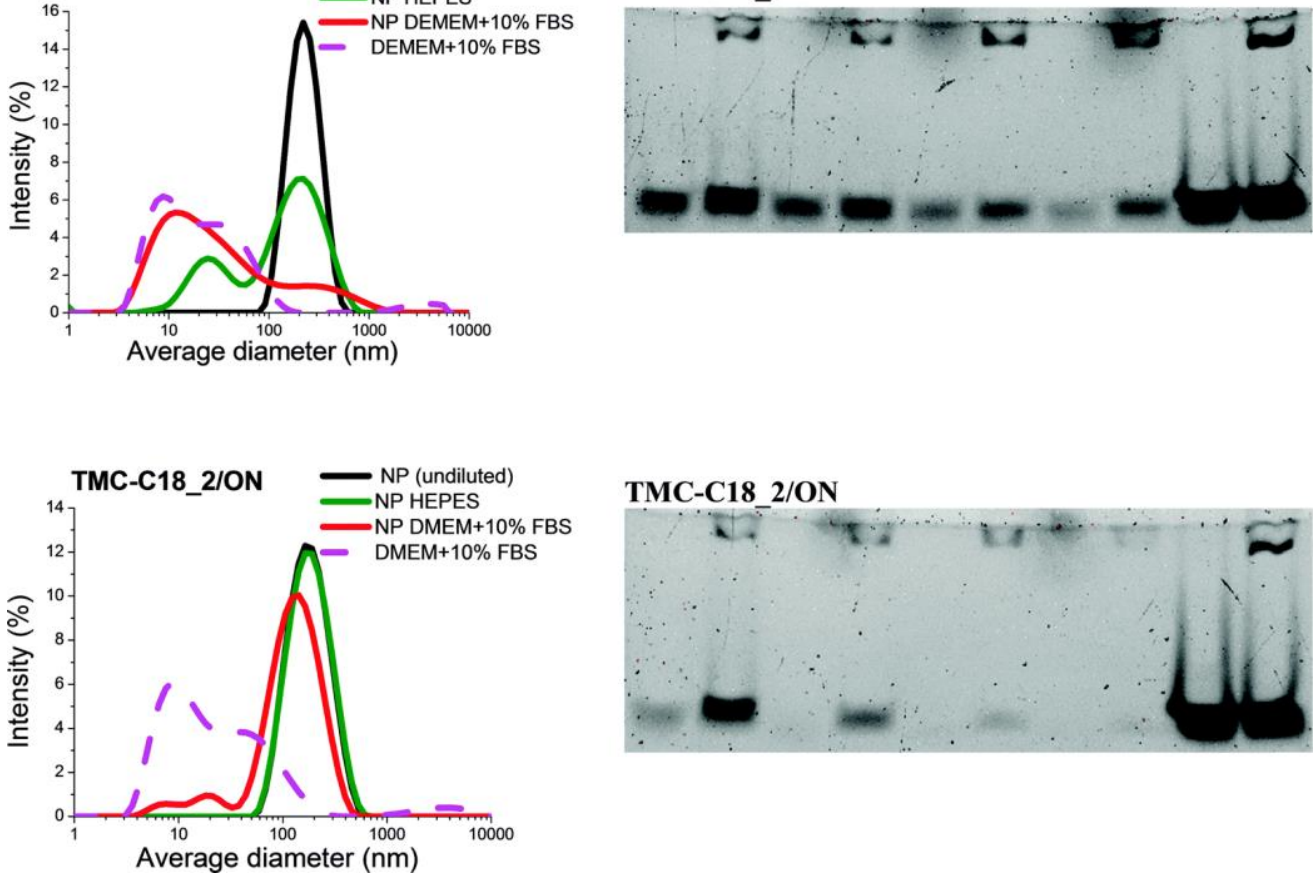

TMC-C18 2/ON

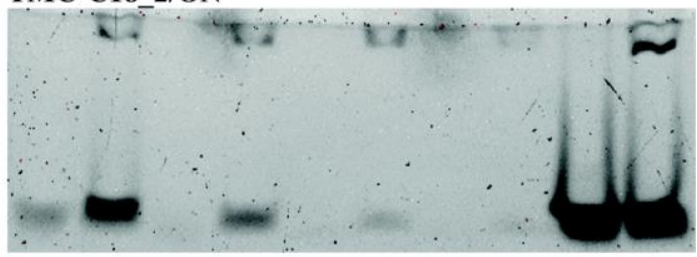

Fig. 6 Stability of complexes in serum-containing medium and HEPES buffer $(\mathrm{pH} 7.40)$ as determined by DLS and PAGE analyses. TMC/ssON complexes having an N/P ratio of 80 were incubated at $37^{\circ} \mathrm{C}$ for $1 \mathrm{~h}$ in cell culture medium containing serum. 


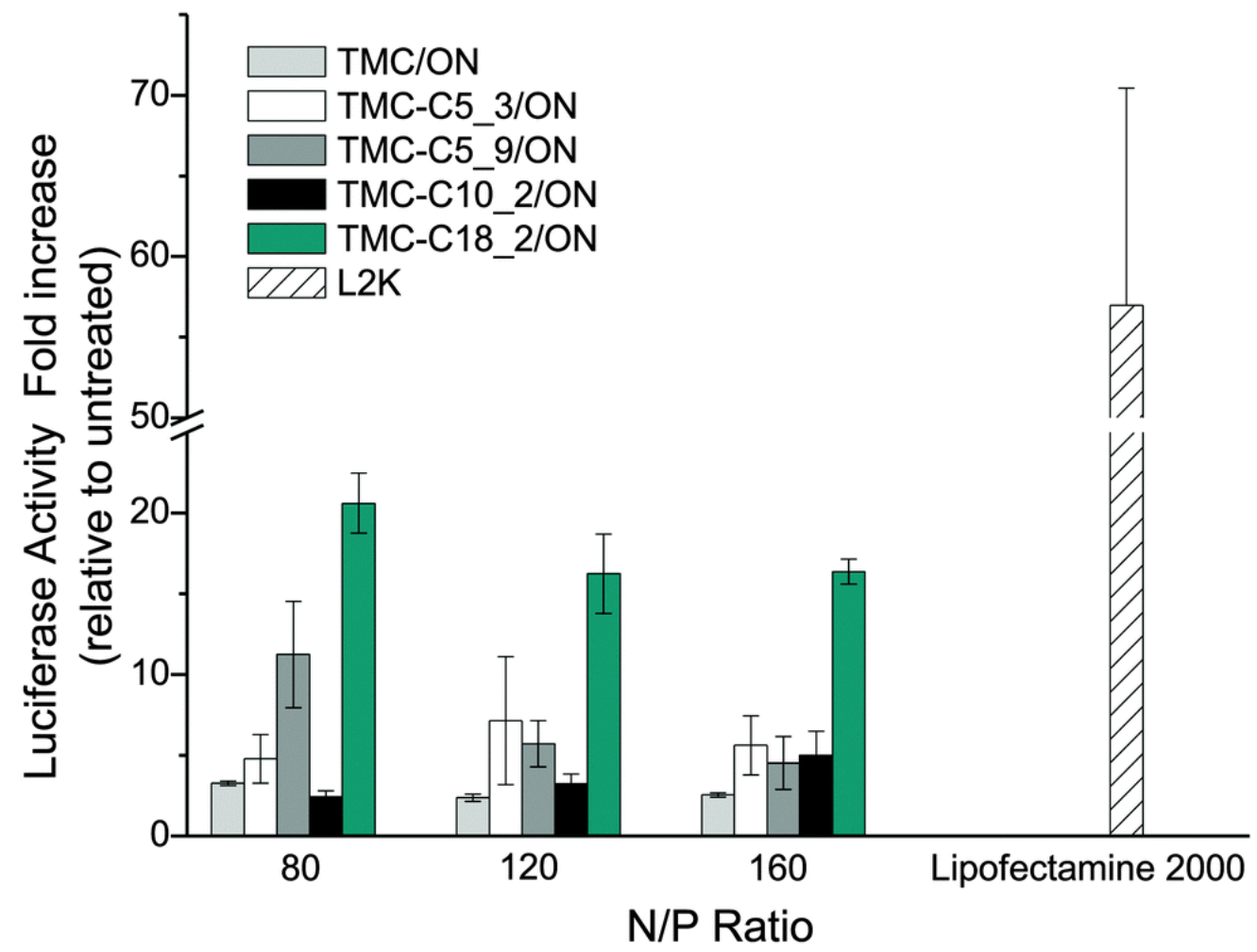

Fig. 7 Splice correction activity of TMC/ssON complexes in HeLa/Luc705 cells. ON was used at the final concentration of $0.3 \mu \mathrm{mol} \mathrm{L}-1$. 


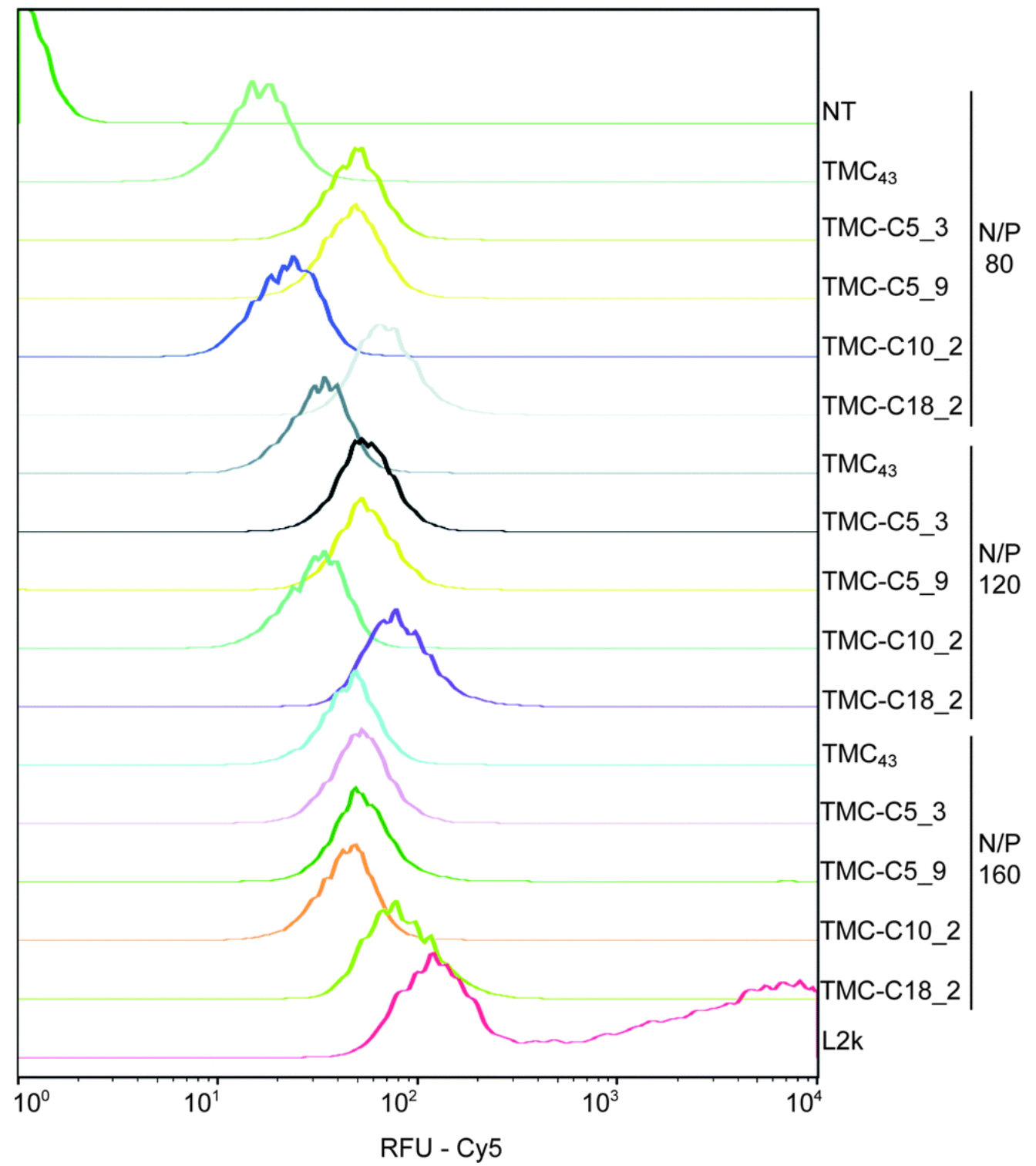

Fig. 8 Characterization of cellular association of TMC/ssON complexes by flow cytometry. Complexes containing Cy5 labeled ON (Cy5-SSO705) were incubated for $24 \mathrm{~h}$ with $\mathrm{HeLa} / \mathrm{Luc70} 5$ cells at a final ON concentration of $0.3 \mu \mathrm{mol} \mathrm{L}-1$. 


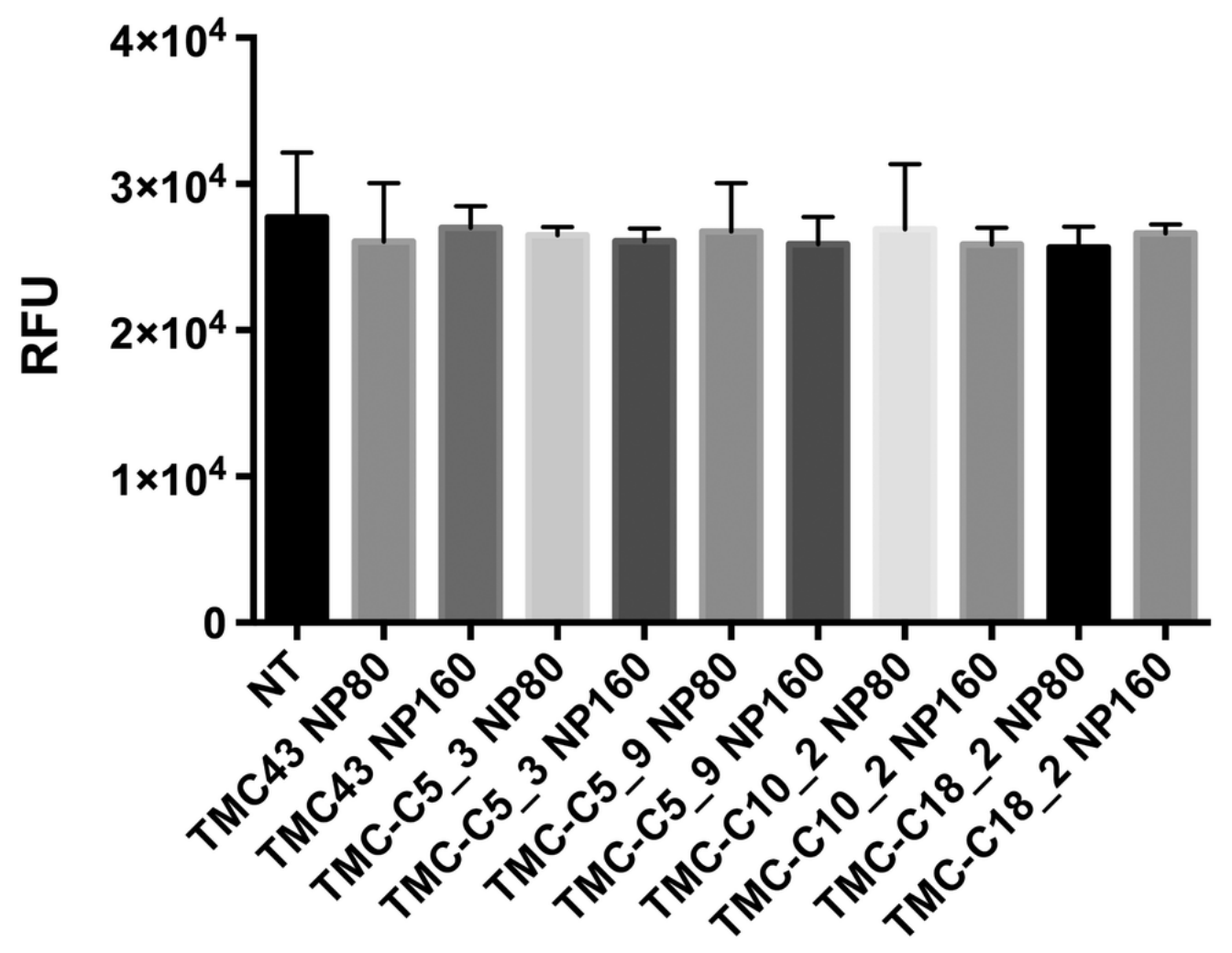

Fig. 9 Cytotoxicity assay as evaluated by metabolic activity determination through resazurin assay. $\mathrm{TMC} / \mathrm{sSON}$ complexes were incubated with $\mathrm{HeLa} / \mathrm{LuC70} 5$ cells for $24 \mathrm{~h}$ at a final ON concentration of $0.3 \mu \mathrm{mol} \mathrm{L}{ }^{-1}$.

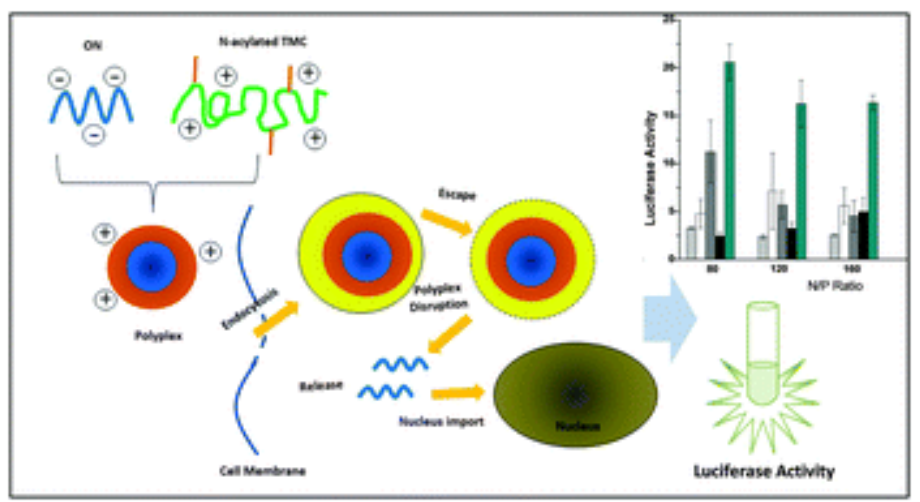


Table 1 Degree of substitution (DS) of TMC-modified polymers estimated by ${ }^{1 \mathrm{H}}$ NMR analysis based on eqn (1)
Sample
$N$-Acyl chain (IUPAC)
$N$-Acyl chain
DS (\%)
TMC-C5_3
Pentanoyl $\left(C_{5}\right)$
Valeoryl $\left(C_{5}\right)$
$3.8 \pm 0.3$
TMC-C5_9
Pentanoyl $\left(C_{5}\right)$
Valeoryl $\left(C_{5}\right)$
$9.1 \pm 1.8$
TMC-C10 2
Decanoyl $\left(C_{10}\right)$
Decanoyl $\left(C_{10}\right)$
$1.7 \pm 0.1$
TMC-C18_2
Octadecanoyl $\left(\mathrm{C}_{18}\right)$
Stearyl $\left(C_{18}\right)$
$2.1 \pm 0.6$

a A higher DS value was observed for TMC- $C_{5}$ samples based on varying the relative concentrations of reagents during the synthesis procedure. 
Supplementary Information

\section{Electronic Supplementary Information}

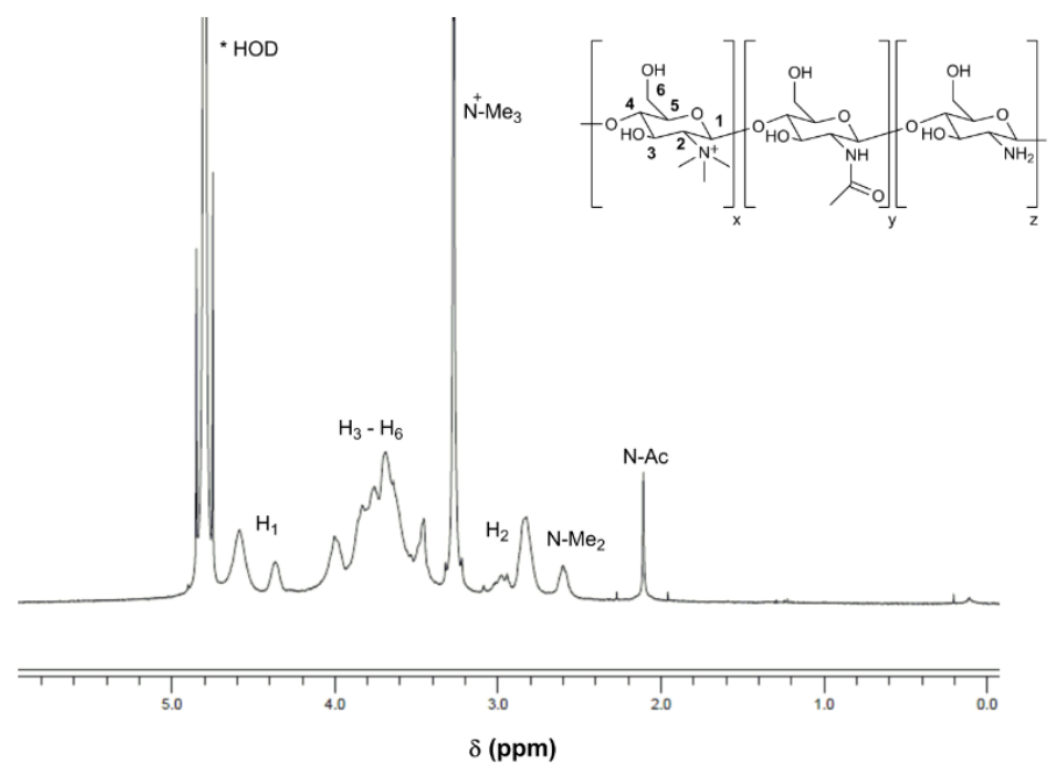

Figure 1S. ${ }^{1} \mathrm{H}-\mathrm{NMR}$ spectra of TMC $\left(\mathrm{D}_{2} \mathrm{O}, 400 \mathrm{MHz}\right)$.

Rua Alfredo Allen, 208 4200-135 Porto 


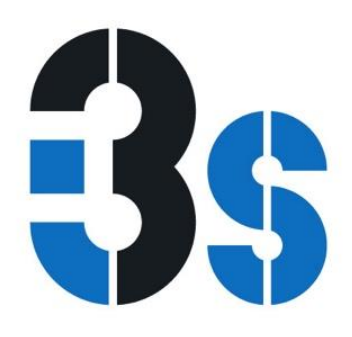

\begin{tabular}{ll|l|l|l|l|l|l|l|l|l} 
N/P & $\mathbf{0 . 5}$ & $\mathbf{1}$ & $\mathbf{2}$ & $\mathbf{3}$ & $\mathbf{4}$ & $\mathbf{5}$ & $\mathbf{6}$ & $\mathbf{8}$ & $\mathbf{1 0}$ & $\mathbf{O N}$ \\
\hline & & & & & & & & \\
TMC & & & & & & & & & &
\end{tabular}

TMC-C5 3

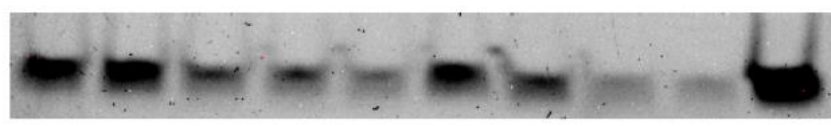

TMC-C5 9

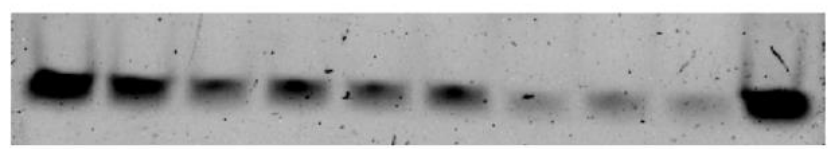

TMC-C10_2

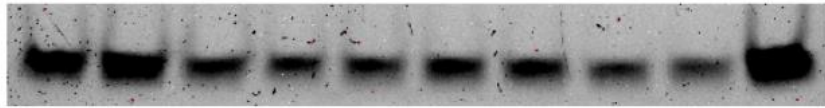

TMC-C18_2

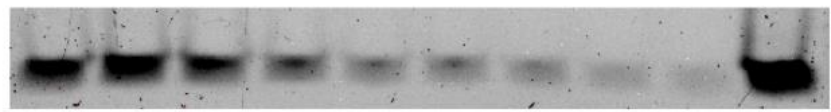

Figure 2S. Polyacrylamide gel electrophoresis was used to examine the oligonucleotide binding capacity of TMC/ssON polyplexes at different N/P ratios prepared in $20 \mathrm{mM}$ HEPES buffer plus $5 \% \mathrm{~m} / \mathrm{v}$ glucose, $\mathrm{pH}=7.4$. 